\title{
On the combination of water emergency wells and mobile treatment systems: a case study of the city of Berlin
}

\author{
Christoph Stallkamp ${ }^{1}$ D . Florian Diehlmann ${ }^{1} \cdot$ Markus Lüttenberg $^{1}$. \\ Marcus Wiens ${ }^{1} \cdot$ Rebekka Volk ${ }^{1}$. Frank Schultmann ${ }^{1}$
}

Accepted: 12 September 2020 / Published online: 7 October 2020

(c) The Author(s) 2020

\begin{abstract}
A shortage of water leads to severe consequences for populations. Recent examples like the ongoing water shortage in Kapstadt or in Gloucestershire in 2007 highlight both the challenges authorities face to restore the water supply and the importance of installing efficient preparedness measures and plans. This study develops a proactive planning approach of emergency measures for possible impairments of water supply systems and validates this with a case study on water contamination in the city of Berlin. We formulate a capacitated maximal covering problem as a mixed-integer optimization model where we combine existing emergency infrastructure with the deployment of mobile water treatment systems. The model selects locations for mobile water treatment systems to maximize the public water supply within defined constraints. With the extension to a multi-objective decision making model, possible trade-offs between the water supply coverage and costs, and between the coverage of differently prioritized demand points are investigated. Therefore, decision makers benefit from a significantly increased transparency regarding potential outcomes of their decisions, leading to improved decisions before and during a crisis.
\end{abstract}

Keywords Humanitarian logistics · Water contamination · Emergency wells · Disaster · GIS · Optimization

Christoph Stallkamp and Florian Diehlmann have contributed equally to this work.

Electronic supplementary material The online version of this article (https://doi.org/10.1007/s10479-02003800-8) contains supplementary material, which is available to authorized users.

Christoph Stallkamp

christoph.stallkamp@kit.edu

1 Institute for Industrial Production (IIP), Karlsruhe Institute of Technology (KIT), Karlsruhe, Germany 


\section{Introduction}

\subsection{Motivation}

Critical infrastructures are organizations and facilities with great importance to the public. Failure can lead to supply shortages of essential services as well as possible disruption of public safety (BMI 2009; UNISDR 2009). In case of an emergency, it is necessary to limit damages to critical infrastructures and to prevent possible corresponding disruptions of services (Wannous and Velasquez 2017). This objective is particularly relevant due to new security policy risks like international terrorism and significant natural risks that have an enhanced potential to damage critical infrastructures (Bross et al. 2019). Therefore, authorities need to update their continuity plans regularly and make sure that each part of the critical infrastructure is protected.

The water supply system and the sewage system are one of the critical infrastructures of a city (BMI 2009). Potential damage to the system can lead to the unavailability of drinking water. For example, a contamination led to disruptions in Toledo (Redfern et al. 2018) and Flint (Ruckart et al. 2019). Moreover, the system can be affected by natural disasters. For example, an earthquake caused significant disturbance of the water system in Los Angeles in 1994 (Davis 2014), a long-lasting drought put the supply in Kapstadt under heavy pressure (Enqvist and Ziervogel 2019). Moreover, severe flooding led to a collapse of the water distribution of Gloucestershire (Rundblad et al. 2010) and Simbach am Inn in Germany (Bross et al. 2019). While a lot of measures and contingencies are in place to repair and reestablish water supply, it is important to develop plans to mitigate the consequences of a disruption.

Drinking water is critical for the survival of the population. Therefore, operators of critical infrastructure are obliged to develop contingency plans. For example, German water supply companies need to implement preventive measures for strengthening the safety of public water supply. If companies lack capacities to re-establish normal operations, German authorities need to ensure alternative supply measures (BBK 2016a).

Dependent on the level of the disruption, authorities can activate a variety of specialized disaster management agencies or divisions. Besides safety and security actors like firefighters, police, or the military, authorities can activate the Federal Agency for Technical Relief (THW), which provides technical support in the context of civil protection and disaster assistance (Deutscher 1990). The agency consists of volunteers that form different specialist groups, including drinking water specialist groups equipped with resources to establish an emergency water supply. These resources include mobile water treatment systems, water transportation containers, and vehicles (BBK 2016a). Other specialist groups provide emergency repair, supply, or rescue (BBK 2016b).

While the Federal Office for Civil Protection and Disaster relief (BBK) coordinates crisis interventions on a national level (BBK 2016b), each federal state in Germany is in charge of their own disaster measures. In case of water supply disruptions, they can, for example, install mobile pipes from regions with functioning water systems or use transportation trucks (BBK 2016b). In severe cases, when a huge number of people cannot be supplied otherwise, German authorities can activate more than 5,200 independent emergency water wells throughout the country that enable quick access to groundwater (Fischer and Wienand 2013).

However, even though measures to maintain and check the wells are in place, it is not certain that each well works properly (Boehme et al. 2012). Moreover, the well system was designed and installed during the cold war (Fischer and Wienand 2013). Even though 
authorities occasionally install new fountains, it can be debated if the locations reflect the current distribution of the population properly. Therefore, the focus of our study is to analyze the effectiveness of wells in a hypothetical disaster and to investigate, how these wells can be supported by a more flexible technology.

\subsection{Problem description and contribution}

Mobile water treatment systems represent a flexible option to complement the emergency supply by wells. However, the decision making on the placement of these mobile systems is highly complex and depends on multiple factors, such as suitable locations, distance to the beneficiaries, or available budget. This is especially complex in disaster relief since parts of the population in different and sometimes critical physical constitution need different types of help [see for instance IFRC (2011), who state that they "prioritize to help the most vulnerable and ensure that immediate emergency needs are being met]." Decision making is especially challenging for authorities responsible for the whole population. While they are focused on maximizing the supply for the vulnerable part of the population, they still need to make sure that the non-vulnerable parts of the population receives sufficient amounts of water or help as well.

Therefore, we developed a multi-criteria decision model to support decision makers in implementing an emergency water supply chain in case of the disruption of the public water supply. This model allows to consider different objectives within the optimization and, therefore, to analyze possible trade-offs (e.g. cost vs. coverage, focus on vulnerable vs. less vulnerable parts of the population).

The model consists of three parts: determination of the spatial demand and the supply of the existing emergency water supply infrastructure, identification of potential locations for mobile water treatment systems, as well as the selection of locations for them.

Consequently, the article contributes to the body of literature in three significant ways. First, we provide a guideline to transparently assess available capacities for the first time to enable decision makers to assess their own systems' conditions and capacities. Second, we develop a novel maximum covering model to support decision makers designing emergency water supply chains. The developed model combines various extensions for the maximum covering location problem. In contrast to previous models, our approach allows to jointly consider existent service infrastructure with additional facilities, while integrating the inventory allocation of facilities to demand points. Third, the importance of considering trade-offs is obvious since authorities need to regard multiple stakeholders and their needs within their decision making. Furthermore, it is necessary to understand the consequences of prioritizing parts of the population. With our methodology, various trade-offs can be identified in a clear-cut way.

The paper is structured as follows. After the review of related literature in the following section, we provide an overview of the model in Sect. 3. Following, we apply the model in the context of a case study for a hypothetical terror attack (water contamination) on the public water supply of the city of Berlin, Germany in Sect. 4. The results of that case study are highlighted in Sect. 5 and discussed in Sect. 6. 


\section{Literature review}

\subsection{Water emergencies}

Jain (2012) highlights the challenge of possible contamination of drinking water sources after an emergency, especially if there is a lack of infrastructure to purify water. He classifies four groups of possible contaminants: (1) microbiological contaminants, (2) chemical contaminants, (3) radiological contaminants, and (4) physical contaminants. Loo et al. (2012) provide a comprehensive overview of water treatment systems that purify water from different contaminants. They also developed a framework to support authorities and relief organizations selecting from the multiple water treatment options in emergencies. Water treatment systems are classified according to their operating principle (Loo et al. 2012) or their capacity, ranging from point-of-use systems for the intervention on a household level to small-scale-systems on community level (Peter-Varbanets et al. 2009).

Several papers analyze the effectiveness of specific water treatment technologies reducing the concentration of water contaminants in different emergency settings. Clasen and Boisson (2006) note that household-based ceramic filters helped to improve the drinking water quality among the population affected by flooding in the Dominican Republic in 2003. Clasen et al. (2006) provide an overview of several water purification technologies deployed after the Indian Ocean tsunami in 2004. They highlight that a timely, comprehensive, and effective response to restore drinking water is essential to save lives and outline conditions under which household water treatment technologies are useful to provide relief to an affected population. Dorea et al. (2009) describe the intervention with a clarifier on a community level and provide performance data from the Indian Ocean tsunami. Garsadi et al. (2009) extend the investigated treatment systems in this aftermath by the discussion of the practical experiences of the deployment of mobile water treatment systems. Mahmood et al. (2011) evaluate household sand filters in the aftermath of an earthquake that damaged over 4000 water and sanitation schemes in northern Pakistan in 2005. Lantagne and Clasen (2013) document the impact of a household intervention with chlorine and filter products distributed after the 2010 earthquake in Haiti.

Since the number of natural and man-made disasters is expected to rise, e.g. due to climate change, migration, diseases or terror attacks, it is necessary to develop holistic concepts to encounter the consequences of the disasters as effectively as possible (Wu et al. 2019). This also includes integrated concepts for drinking water supply and water treatment technologies.

\subsection{Covering approaches}

According to Church and Murray (2019), public actors' location decisions are often formulated as covering problems to represent the principle of equity while placing public facilities and services. There are two types of location covering models, Location Set Covering Problems (LSCP) and Maximal Covering Location Problems (MCLP). While LSCPs seek to cover total demand while minimizing the number of facilities needed, MCLPs maximize the covered demand based on a given number of facilities (Church and Murray 2019).

According to Toregas (1970), an application of the LSCP is placing emergency response services with a maximal accepted service time. Other applications are ensuring the access of services for people with disabilities (Kwan et al. 2003), the siting of bus stops (Murray 2001), or the placing of warning sirens (Current and O'Kelly 1992). 
On the other hand, possible applications for the MCLP are the placing of health clinics (Bennett et al. 1982) or fire stations (Murray 2013) in case only a limited number can be set up. Church and ReVelle (1974) suggest that MCLPs for given planning applications can be solved by varying the number of facilities. This allows to create a trade-off between the coverage provided and the investment in facilities (Church and Murray 2019). This additional information allows the decision maker to weigh between service level and cost.

$\mathrm{Li}$ et al. (2011) provide an overview of various extensions of the MCLP and LSCP like implementing quality levels of service, multiple types of service, or ensuring back up coverage. Moreover, Church and Murray (2019) mention extensions regarding integrating existing service systems and hierarchical services.

Loree and Aros-Vera (2018) highlight that allocating inventory from facilities to demand points is another important aspect while designing post disaster humanitarian supply chains. Integrating the inventory allocation decision into the facility location decision links the optimization of facility locations with the consequences for the supplied population (Lin et al. 2012). Loree and Aros-Vera (2018) discuss three models with the objective to maximize the covered demand (Jia et al. 2007; Murali et al. 2012; Hong et al. 2012). Only Jia et al. (2007) and Hong et al. (2012) base their models on possible facility locations and specify the numbers of facilities that are to be placed. However, none of the models considers multiple facility types to meet the demand and none considers trade-offs.

Consequently, our MCLP differs from available humanitarian location-allocation models by including the following model components: it determines facility locations, while simultaneously considering multiple facility types that combine efforts to provide relief and maximize coverage. In addition, capacity constraints, the allocation of inventory to the demand points, and multiple sourcing are included. Furthermore, we extended the MCLP model to include a multi-criteria perspective, allowing for trade-off analysis.

\subsection{Multi-objective approaches}

Real-world problems include multiple objectives that decision makers have to consider. The resulting multi-criteria decision making (MCDM) problems combine decisions regarding cost, environmental risk, service level, or other aspects (Clasen et al. 2006).

Various studies used MCDM methods to find optimal solutions for different emergency settings. Barbarosoğlu et al. (2002) develop a mathematical model for helicopter mission planning during disaster relief operations. The model has two sub-problems with conflicting objectives leading to the additional development of a multi-criteria analysis. Evaluating another use case, Bastian et al. (2016) create a multi-criteria decision analysis framework to optimize the military humanitarian assistance aerial delivery network.

Emergencies in the context of water are also investigated, including hazards and public water supply. Gigović et al. (2017) evaluate possible flooding areas in urban areas by defining factors that are relevant to the hazard of flooding combining the application of geographical information systems (GIS) and MCDM. Doerner et al. (2009) investigate the placement of public locations near coasts taking risks of inundation by tsunamis and costs into account. Singh et al. (2018) evaluate groundwater potential while Al-Weshah and Yihdego (2018) investigate different approaches to remediate water supply after groundwater pollution. Tscheikner-Gratl et al. (2017) investigate a multi-objective approach for the maintenance of water supply systems, while Zimmermann et al. (2018) assess different water infrastructures. Nolz et al. (2010) introduce a decision support system for planning water distribution 
tours with trucks in emergencies. The transportation problem includes a cost criterion based on travel time and a coverage objective.

Boonmee et al. (2017) provide a comprehensive overview of location-based decision making problems that are related to humanitarian logistics in emergencies. The survey is based on data modeling types and the classification of facility location problems. Furthermore, it examines pre- and post-disaster situations (Boonmee et al. 2017) and includes multicriteria problems. None of the mentioned approaches regard the trade-off between differently vulnerable groups of the population.

Furthermore, Holguín-Veras et al. (2013) provide an overview of humanitarian logistics problems with multiple objectives. They discuss incorporating a measure into optimization problems, which represents the suffering of the population experienced from a lack of access to goods or services, and name this external effect deprivation cost. Therefore, deprivation cost functions present an opportunity to prioritize parts of the population (Rivera-Royero et al. 2016). Shao et al. (2020) provide an overview of the recent literature on the concept of deprivation cost and highlight challenges associated with this approach. They conclude that deprivation cost functions are highly sensitive towards the product and the local economic characteristics (Shao et al. 2020).

To the best of our knowledge, no estimation for water deprivation cost functions in Germany is known. Hence, the application of a deprivation cost approach does not seem to be mature enough in our context.

\subsection{Research gap}

The literature review shows that there are no covering models that provide an integrated concept of combining existing infrastructure with additional mobile water treatment systems. The developed model allows decision makers to consider already existing infrastructure when deciding where to place additional mobile water treatment resources in an emergency or undersupply case.

With the extension of the MCLP model to a MCDM model, comprehensive trade-off analysis with different priorities are enabled. To the best of our knowledge, there is no such model combination allowing for a comprehensive analysis of trade-offs between coverage and length of supply routes, number of deployed water treatment systems or costs. Our approach also provides valuable insights into the prioritization of certain demand points over others, especially if deprivation cost functions cannot be applied.

\section{Methodology}

The model consists of three modules that are described in the following subsections. The modules (A) and (B) feed the module (C) that consists of the optimization model and enables trade-off analysis.

\subsection{Model requirements}

The introduced model aims to support the establishment of a humanitarian supply chain in the context of an urban water emergency. Modeling an emergency supply chain for a major city involves the definition of model boundaries, the collection of required data, and the formulation of assumptions due to prevailing unknowns and uncertainty. 


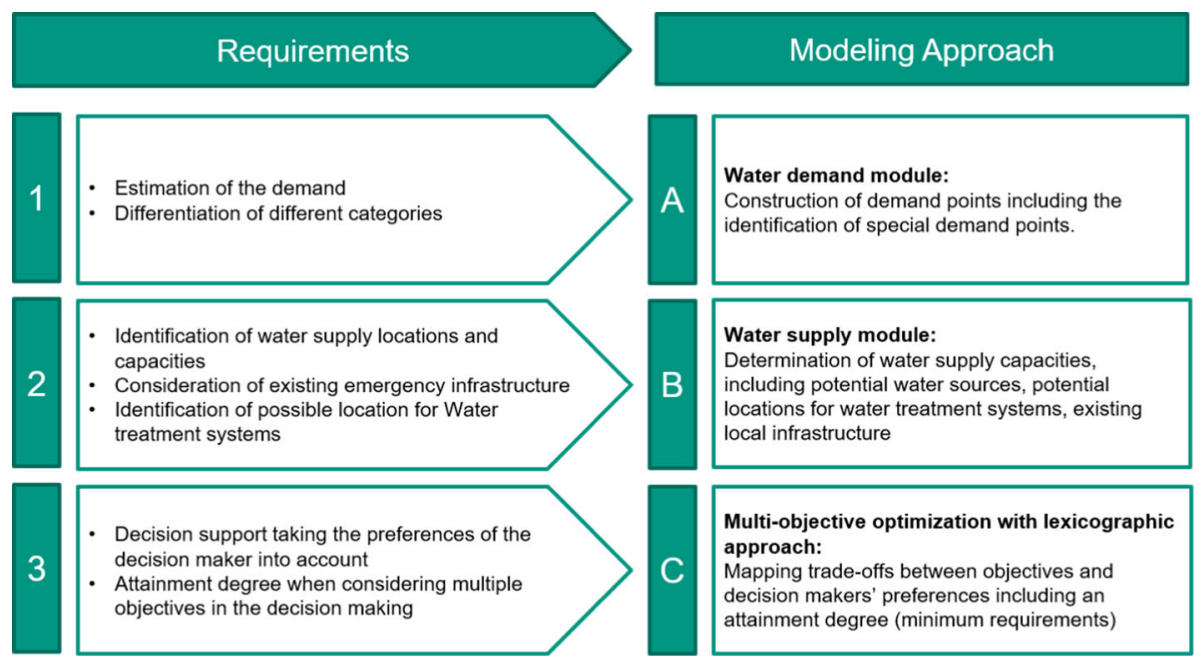

Fig. 1 Overview of model requirements and modules with the chosen modeling approaches (modules A, B, C). The requirements are discussed above and are based on the challenges identified when while designing a water emergency supply chain. Three model modules are formulated and described to meet the requirements

The main objective is the maximization of the coverage of the public water demand. In covering models, demand is covered and supplied within a predefined service standard. The demand coverage is maximized by placing mobile water treatment systems throughout the city while taking already existing and functioning emergency infrastructure (wells) into account.

The main challenges are estimating demand, identifying and locating water supply capacities, and determining preferences of the decision maker. The model is supposed to fulfill the following requirements:

1. Estimating demand and identify demand centers within the study area. This includes different categories of demand such as the demand of residents and patients of high vulnerable facilities such as hospitals and nursing homes.

2. A second requirement is establishing the available drinking water within the study area. Possible drinking water sources are already existing emergency infrastructure and location candidates for mobile water treatment systems.

3. Besides optimizing the total water demand covered, the consecutively optimization of secondary objectives should be possible to allow analyzing trade-offs between the attainment of multiple objectives. This enables the decision maker's preferences to be represented. Possible trade-offs could be the maximum coverage at a given budget or at least to gain knowledge on how much a higher coverage would cost.

\subsection{Model components}

Figure 1 displays an overview of the model requirements and contrasts them with the chosen modelling approaches to meet these requirements. The water demand module (A) and the water supply module (B) are two modules to determine the required data for the optimization module (C). Module (A) locates the water demand by constructing demand points based on collected data while taking two different categories of demand into account. Module (B) eval- 

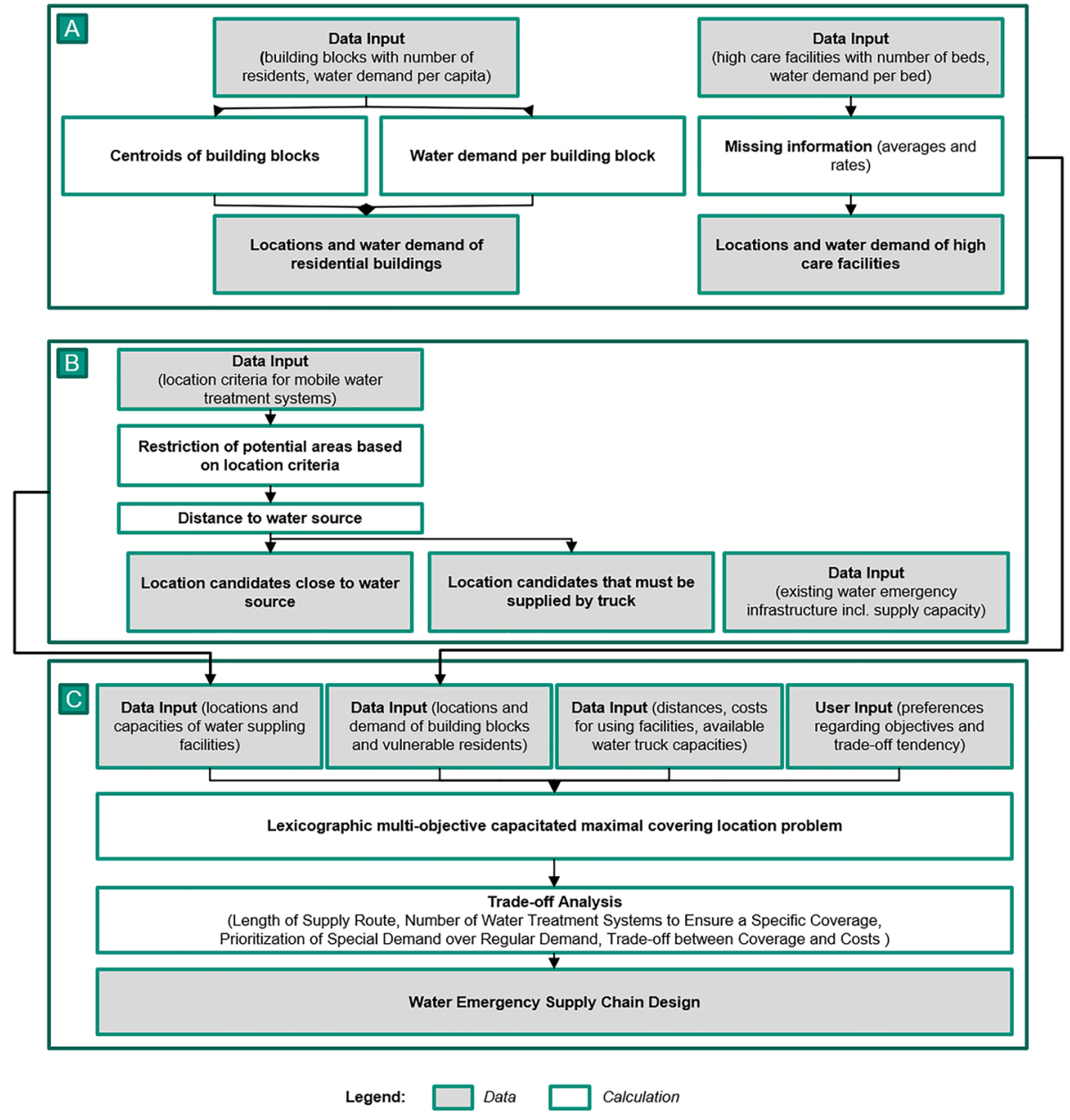

Fig. 2 Overview of the model and the decision making process. Water demand module (A) and Water supply module (B) provide data for the optimization module (C). The decision making process is based on a multiobjective optimization problem and trade-off analysis

uates water supply capacities with respect to their locations and costs. Furthermore, existing emergency infrastructure is investigated and possible locations for mobile water treatment systems are defined as solution space. Module (A) and (B) represent the data basis for module $(\mathrm{C})$. The core of module $(\mathrm{C})$ is a lexicographical optimization model comprising two objectives, enabling a consecutive optimization of coverage and associated costs. It allows the mapping of trade-offs between objectives and the impact of the decision maker's preferences. Figure 2 displays the interdependencies of the different modules that are described in more detail below.

Module (A) determines the demand in case of an emergency. Based on data for population density per building blocks and the water demand per capita, demand centers can be localized and their water demand can be calculated resulting in the water demand of regular residents. Vulnerable patients of hospitals and nursing homes are located at these high care facilities. 
Their demand is characterized by the number of beds per institution and the per bed demand. Additional demand flows can extend the approach.

The available water supply by existing emergency wells is established by module (B). Data must be identified that locate the existing emergency infrastructure and its capacities. Possible locations for mobile water treatment systems are defined by identifying open areas and by restricting potential candidates based on location criteria such as access to the road network or a water source. The opportunity to supply locations by tank trucks is evaluated.

The decision making process is described, summarized and solved in module (C). The established data from modules (A) and (B) is input for a capacitated maximal covering location problem (CMCLP). A CMCLP was chosen since covering models are typically used to design emergency services (Daskin 2008). Church and Murray (2019) justify this with the goals of the public sector, including the provision of good services and fairness that are implemented through a service level. Moreover, a MCLP is formulated since the number of available mobile water treatment systems is limited in case of an emergency. Demand is regarded as covered if the nearest supply is within a predefined distance and provides a predefined minimum of water.

If emergency infrastructure exists, the model extends this by placing mobile water treatment systems. These two different facility types have both specific supply capacities. Multiple facilities can provide service for one demand point.

Chung et al. (1983) describe a basic formulation of CMCLP. Their basic formulation was extended by additional constraints leading to the following optimization model (see Table 1 for a description of the components).

$$
\begin{array}{rlrl}
\text { maximize } & \sum_{i \in I} \sum_{j \in N_{i}} z_{i j} * a_{i} & & \\
\text { subject to } \sum_{j \in N_{i}} z_{i j} \leq 1, & & & \\
z_{i j} \geq y_{i j} * f d, & & \forall i \in I, \forall j \in N_{i}, \\
\sum_{i \in K_{j}} a_{i} * z_{i j} \leq c_{j} * x_{j}, & & \forall j \in J, \\
\sum_{j \in J} s_{j w} \leq c_{w}, & & \forall w \in W S, \\
\sum_{w \in W} s_{j w} \leq 1, & & \forall j \in J, \\
s_{j w} \leq a l_{j w}, & & \forall j \in J, \forall w \in W S,, \\
\sum_{w \in W S} s_{j w} \geq x_{j}, & & \forall j \in J, \\
\sum_{j \in J} x_{j} \leq p, & & \forall j \in J, \\
\sum_{j \in D W T} x_{j} \leq q, & & \forall j \in J, \\
z_{i j} \leq x_{j}, & & \forall i \in I, \forall j \in N_{i}, \\
y_{i j} \geq z_{i j}, & & \\
y_{i j} \leq z_{i j} * M, & & \forall i \in I, \forall j \in J, \\
\sum_{j}, \forall, &
\end{array}
$$


Table 1 Notation of sets, parameters and variables used in the optimization model

$\begin{array}{ll}\text { Sets } & \\ i & \text { Index of demand points }(i \in I) \\ j & \text { Index of water supplying facilities }(j \in J) \\ w & \text { Index of water source }(w \in W S) \\ N_{i} & \text { Set of water sources within service standard of demand } \\ & \text { point } i\left\{j \mid d_{i j}<S\right\} \\ K_{j} & \text { Set of demand points within service standard of water } \\ & \text { supplying facility } j\left\{i \mid d_{i j}<S\right\} \\ F T & \text { Set of existing emergency supply locations }\{j \mid \text { supplying } \\ & \text { facility } j \text { is part of the existing infrastructure }\} \\ W T & \text { Set of available water treatment systems }\{j \mid \text { supplying } \\ & \text { facility } j \text { is a water treatment system }\} \\ D W T & \text { Set of available water treatment systems that must be } \\ & \text { supplied by trucks }\{j \mid j \in \text { WT and distance to water } \\ & >d W\}\end{array}$

Parameters

$d W$

Maximal distance allowed for pump supply of water treatment system

$d_{i j}$

Shortest distance between demand $i$ and supply $j$

$a l_{j w}$

Binary allocation of supplying facility $j$ to water source $w$
$a_{i} \quad$ Amount of demand at demand point $i$
$c_{j} \quad$ Capacity of water supply facility $j$
$c_{w} \quad$ Maximum number of water treatment systems that can be supplied by water source $w$
$S \quad$ Desired maximum distance between supply and demand
$p \quad$ Maximum number of water treatment systems to be placed in total
$q \quad$ Maximum number of water treatment systems that can be supplied by available trucks
$f \quad$ Minimum percentage of demand that must be supplied by an allocated facility within the service standard

$M \quad$ Big number with $\mathrm{M}>1000$

Decision variables

$\begin{array}{ll}x_{j} & \begin{cases}1, \text { if water treatment system is located at } j \\ 0, \text { otherwise }\end{cases} \\ x_{j} & \begin{array}{l}1, \text { if demand } i \text { is allocated to facility } j \\ 0, \text { otherwise }\end{array} \\ y_{i j} & j \in F T\end{array}$


Table 1 continued

\begin{tabular}{ll}
\hline$s_{j w}$ & $\left\{\begin{array}{l}1, \text { if location } j \text { is allocated to water source } w \\
0, \text { otherwise }\end{array}\right.$ \\
$z_{i j}$ & Percentage of demand $i$ assigned to facility $j$
\end{tabular}

$$
\begin{aligned}
& x_{j} \in\{0,1\}, \quad \forall j \in J, \\
& y_{i j} \in\{0,1\}, \quad \forall i \in I, \forall j \in J, \\
& z_{i j} \geq 0, \quad \forall j \in J \text {. }
\end{aligned}
$$

The objective function of the CMCLP is to maximize the total demand covered (1). It is subject to the constraint that a demand point is satisfied by a water source that is located within a certain distance and receives an amount of water that is lower or equal to its total demand (2). Therefore, an oversupply is not possible. Moreover, constraint (3) establishes that the water allocated to a demand point is higher than a percentage that can be predefined dependent on the context of the case study. Trips for very small quantities of water are thereby eliminated. Therefore, people are sure that if they take a trip to a water supply facility, they will get an adequate amount of water. Due to this combination of constraints, the demand can be covered or partially covered by one or multiple sources within an acceptable distance.

Water supplying facilities have a predefined capacity that must not be exceeded (4). In addition, constraint (5) ensures that the capacities of water sources are not exceeded by the number of water treatment systems placed next to it. Each location is allocated to one water source (6) while the allocation is only possible if it is feasible with respect to other emergency systems placed at the same water source (7). Constraint (8) establishes that if a water treatment system is placed at a location, this location must be allocated to a water source.

A maximal number of $p$ water treatment systems can be sited (9), of which $q$ can be placed further away from water than a specified distance (10). Constraint (11) restricts the allocation of demand to available emergency infrastructure and locations where a water treatment system has been placed.

Constraint (12) defines a lower bound and constraint (13), an upper bound for the decision variable $y_{i j}$. Constraints (14) to 16 define the range of values of the decision values.

Due to the constraints described above, it is possible that the available resources are not sufficient to supply a desired proportion of the population. In Sect. 6.2, we discuss this issue and suggest a model to analyze this further if decision makers want to extend their analysis in this direction.

Furthermore, the problem is extended to a multi-objective problem that is solved using a lexicographic approach, optimizing the objectives coverage and costs in a defined sequence. This enables the investigation of possible trade-offs between different objectives (Farahani et al. 2010). Table 2 introduces additional parameters to enable the trade-off analysis.

In general, a lexicographic solution approach optimizes multi-objective problems sequentially in a predefined order and, therefore, it is based on the preferences of the decision maker. The present model assumes that the decision maker prioritizes coverage higher than cost in the case of a terror attack or emergency. The coverage is optimized while the cost objective is not considered. If multiple solutions result in an optimal coverage, the cost objective is 
Table 2 Extended notation to enable trade-off analysis: Multi-objective optimization approach, inclusion of costs and analysis of water treatment systems needed to achieve a defined coverage

\section{Parameters}

Multi-objective optimization

perCov

Attainment degree of optimal coverage solution (percentage)

Costs

costEW

Daily cost of operating existing emergency water supply infrastructure $(F T)$

$\cos \mathrm{LW}$

Daily cost of operating a water treatment system not supplied by trucks $(W T \backslash D W T)$

costLC

Daily cost of operating a water treatment system supplied by trucks $(D W T)$

Number of Water Treatment Systems

perTotalCov Percentage of the total demand that must be covered

optimized within the determined solution space (Nickel et al. 2011). An objective attainment degree can extend this approach. Table 2 introduces the parameter perCov that represents an objective attainment degree and allow deviation from the optimal solution of the demand covered to enable possible cost savings.

The following equations (17) to (18) display the additions to establish the subsequent cost minimizing optimization run.

$$
\begin{aligned}
& \operatorname{minimize} \operatorname{cost} E W * \sum_{j \in F T} x_{j}+\operatorname{cost} L W * \sum_{j \in W T} x_{j}+\operatorname{cost} L C * \sum_{j \in D W T} x_{j} \\
& \text { subject to } \sum_{i \in I} \sum_{j \in N_{i}} z_{i j} * a_{i}=\operatorname{per} \operatorname{Cov} * \text { Optimal Coverage }
\end{aligned}
$$

The first step of the lexicographic solution approach maximizes the demand covered as defined in equations (1) to (16) and the optimization approach described above. The coverage of its optimal solution is then set to the objective attainment degree in equation (18). The second step of the approach is minimizing the associated cost for the given coverage. Therefore, objective function (17) is introduced. Constraint (18) enforces that the set coverage is achieved. The full optimization model for minimizing the total costs also includes constraints (2) to (16).

\section{Case study}

In the following, the consequences of a hypothetical terrorist attack on the water supply infrastructure of Berlin, Germany, is investigated. The city of Berlin is assumed to be a prestigious target for a terrorist attack, as it is the capital of Germany, with over 3 million registered residents (Amt für Statistik Berlin-Brandenburg 2019b) in the center of Europe. Therefore, the city is a suitable case study for the application of the introduced optimization model and for planning an emergency water supply chain. 


\subsection{Berlin and its emergency management processes}

According to the Berliner Wasserbetriebe (2019), the average water consumption of a Berlin resident is a total of 110 liters per day. Drinking water and water used to prepare food are 5.5 liters, whereas most of the water is used for personal hygiene or sanitary facilities. Water supply is ensured by nine waterworks that gain water from bank filtrate, which is extracted indirectly from surface water. Its quality depends on the condition of lakes and rivers next to the waterworks (Hiscock and Grischek 2002). Thus, if the surface water is contaminated, there is a possibility of a disruption of the public water supply (Möller and Burgschweiger 2008).

The responsibility of water supplying companies includes preventive measures for strengthening the safety of the public water supply (BBK 2016a). If a disruption or failure of the public water supply can no longer be controlled by the water supply company, the municipality, district, or state may assist with alternative supply measures (BBK 2016a). In that case, federal agencies like the THW are deployed, and existing emergency infrastructure is activated (BBK 2016b).

The THW can provide mobile water treatment systems to establish an emergency supply. The deployment of these systems results in the need for alternative water sources providing water to gain drinking water. In the city of Berlin, surface water is a valuable water source for purification systems, since it is easily accessible due to significant water surfaces $\left(58.48 \mathrm{~km}^{2}\right)$ in and around the city (Amt für Statistik Berlin-Brandenburg 2020). Surface water is usually the most polluted water, leading to stricter requirements for purification technologies (Dorea et al. 2009). If there is no time to identify possible contaminants within the water, a purification system that purifies a broad spectrum of contaminants should be preferred. Riley et al. (2011) recommend the use of multi-barrier techniques. This technique is, for instance, included in the UF-15 system of the THW (Al Naqib 2019). Consequently, different levels of contamination can be purified simultaneously, allowing supply to the UF-15s from various sources of water around Berlin. Depending on the severity of the emergency, using multiple sources such as lakes, rivers, or even ground water can increase the available capacity while simultaneously not depleting single local water resources. ${ }^{1}$

Groundwater is usually the preferred source due to less exposure to contamination than surface water (Doerner et al. 2009). Emergency water wells ensure the availability of groundwater in Berlin during disruptions of public life and water supply shortages (Fischer and Wienand 2013). According to Fischer and Wienand (2013), there are more than 900 emergency wells in the city of Berlin.

\subsection{Emergency scenario}

The investigated emergency scenario comprises the failure of the public water supply of the city of Berlin after a terrorist attack on the waterworks of the city. As time is needed to run different detection methods to identify the contaminants, the water supply is shut down and an emergency water supply network has to be established in the meantime.

We assumed that the groundwater is not contaminated. Therefore, the emergency water wells can be operated. The large water surfaces of the city of Berlin are additional water sources, but treatment systems are needed to ensure drinking water quality. The UF-15 treatment systems of the THW are used to extend the existing infrastructure of emergency

1 Note that cities with only one source of water (e.g. Las Vegas with Lake Mead) cannot take advantage of this increased flexibility. 
wells. The water is distributed at the wells and treatment systems. The locations of the wells are fixed, whereas the UF-15 systems can only be placed at locations that fulfill specific requirements (see Sect. 4.3.3).

We assumed that besides the public water supply, no other public infrastructure like roads or power supply was attacked. Roads are accessible and power is available everywhere. The accessible roads imply that neighboring communities or other federal states could provide help by supplying bottled water, water tanks, or other resources. The supply of bottled water is not evaluated since it is not under control of the local authorities. However, knowledge and equipment stationed in other federal states are deployed and increase the available capacities of the authorities. The running power supply implies that wastewater treatment systems can be used for the disposal of sewage. Therefore, the water sources will not get contaminated with wastewater.

During the crisis, all businesses in the need of drinking water stay closed as their constant water supply cannot be guaranteed (e.g. hairdresser, ...). However, food supply, pharmacies, hospitals (critical infrastructure) and businesses in the service sector remain opened. Residents are informed in time so that there is no increase in diseases or other sufferings due to consumption of contaminated water. Since the attack was not expected, we assume that private households did not store additional water to complement the emergency water supply.

\subsection{Data collection}

The data collected consists of the demand structure, the available emergency wells, location candidates for available water treatment systems and distances between supply and demand. The following subsections provide an overview of the data while details of the collection and processing can be found in the supplementary material.

\subsubsection{Demand structure}

In Germany, the First German Water Securing Regulation (1. WasSV) determines the amount of water that must be provided to the public in case of an emergency. It distinguishes between regular persons and persons in highly vulnerable facilities. In our context, we regard hospitals or nursing homes as vulnerable facilities, as suggested by the Inter-Agency Standing Committee (IASC 2010) and the Active Learning Network for Accountability and Performance in Humanitarian Action (Sanderson et al. 2012). Regular persons are supplied 15 liters per day while persons in highly vulnerable facilities are supplied 75 liters per day. Residents of vulnerable facilities are provided with 150 liters of water per day if it is an intensive care facility.

Within the attached supplementary material, the collection and processing of the data to establish discrete demand points for the different demand types is described in detail. The emergency water demand of the regular residents is 56.23 million liters per day, whereas the demand of high and intensive care facilities is 6 million liters per day. It has to be mentioned that people also store water at home that, in theory, reduces the required amount of water that authorities need to deliver to ensure the well-being of their population. However, we still regard the full demand of water due to observations made during the first wave of the COVID19-pandemic. Since people panicked and started to purchase goods that the they did not directly need (e.g. toilet paper), we assume that people would still try to receive water if they need it and the state offered it to them for free. 
Table 3 Daily costs of operating one emergency water well

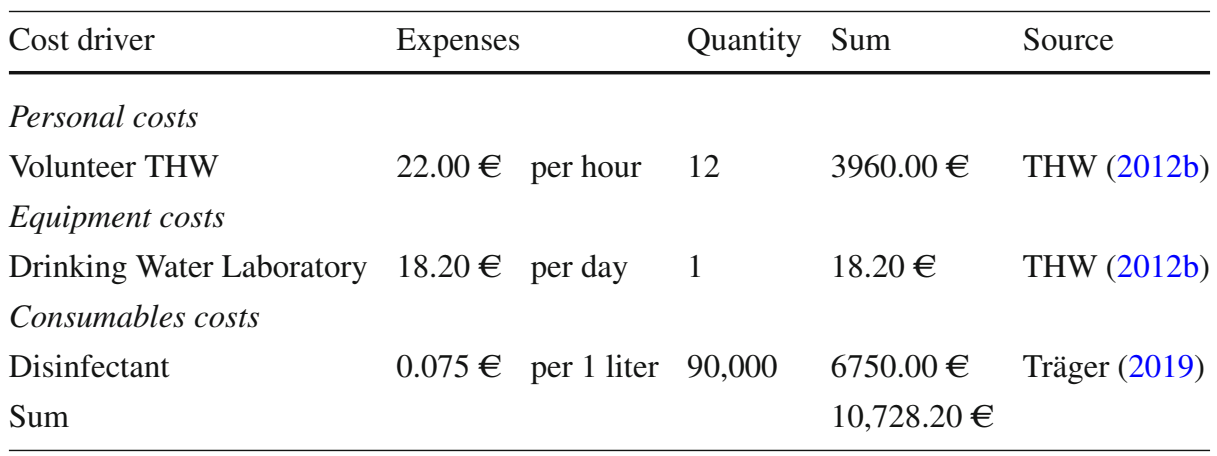

To avoid unnecessary trips, a predefined percentage ensures that, if demand is allocated to a water supplying facility, an adequate amount of water is supplied per person. We assume that a threshold of $20 \%$ of the German standard for water quantity is suitable, resulting in 3 liters per person and day. This is in line with Sphere Project (2018), that defines 3 liters as the absolute minimum in the aftermath of a disaster.

The analysis of demand is limited to the stated types of facilities. Water supply for schools, food suppliers, or industry is not investigated due to the assumption that these facilities are closed during the response phase.

\subsubsection{Emergency wells}

The emergency water supply chain combines existing infrastructure with mobile water treatment systems. The existing infrastructure for water emergencies includes 1028 emergency wells that are placed throughout the city of Berlin. Their average drinking water output is 90,000 liters per day and well (Langenbach and Fischer 2008).

The supplied water will be disinfected with chlorine if needed (Langenbach and Fischer 2008). It is assumed that the legal maintenance procedures have been followed and that, therefore, all emergency water wells considered in the optimization model can be accessed and operated. If this would not be the case, the model parameters can be easily updated and the optimum locations of water treatment systems for maximum coverage can be recalculated.

The daily costs associated with the operation of an emergency water well are separated into personal costs and costs associated with equipment and consumables. Table 3 summarizes the estimated expenses that amount to a rounded 10,700€ per day per operated well. Based on the assumption that all 1028 emergency wells are operated during the maximum of 12 hours per day, fixed supply costs of $11,308,000 €$ per day arise that can not be influenced by the model. The details of the calculation are outlined in the supplementary material.

\subsubsection{Mobile water treatment systems}

The THW has 14 drinking water specialist groups, each of which has a UF-15 drinking water treatment system. ${ }^{2}$ Since the THW is under the control of the German Ministry of Interior, authorities can control the availability and maintenance of UF-15. Therefore, there is no

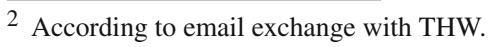


Table 4 Location criteria for location of water treatment systems

\begin{tabular}{|c|c|c|c|}
\hline Criterion & Description & Value & Source \\
\hline Access to water & $\begin{array}{l}\text { Ability to feed water } \\
\text { treatment systems with } \\
\text { water must be ensured. } \\
\text { Therefore, it must be } \\
\text { possible to bridge the } \\
\text { distance between water } \\
\text { source and system with } \\
\text { a pump. Alternatively, } \\
\text { delivery by truck can } \\
\text { be ensured by the } \\
\text { proximity of the road } \\
\text { network }\end{array}$ & $1200 \mathrm{~m}$ & $\begin{array}{l}\text { Corsten and Gössinger } \\
\text { (2016), } \\
\text { Feuerwehrschulen } \\
\text { (2018) }\end{array}$ \\
\hline Access road network & $\begin{array}{l}\text { Transportation of water } \\
\text { to the water treatment } \\
\text { system must be } \\
\text { possible if it can not be } \\
\text { supplied water by } \\
\text { pump. Therefore, the } \\
\text { maximal distance to } \\
\text { next road must not } \\
\text { exceeded the maximal } \\
\text { distance a pump can } \\
\text { bridge }\end{array}$ & $1200 \mathrm{~m}$ & $\begin{array}{l}\text { Corsten and Gössinger } \\
\text { (2016), } \\
\text { Feuerwehrschulen } \\
\text { (2018) }\end{array}$ \\
\hline Distance to demand & $\begin{array}{l}\text { Location candidates } \\
\text { must be within the } \\
\text { maximal allowed } \\
\text { supply routes to at least } \\
\text { one demand point }\end{array}$ & $2000 \mathrm{~m}$ & $\begin{array}{l}\text { EPA (2011), Fischer and } \\
\text { Wienand (2013) }\end{array}$ \\
\hline Available area & $\begin{array}{l}\text { Operating site must have } \\
\text { a minimum size }\end{array}$ & $60 \times 60 \mathrm{~m}$ & EPA (2011) \\
\hline
\end{tabular}

competition with private stakeholders who want to support their processes by purifying water themselves. And, if a water treatment system would be unavailable, e.g. due to an unexpected breakdown, the model parameters can be easily updated and the optimum locations of water treatment systems for maximum coverage can be recalculated.

The UF-15 treats well or surface water using ultrafiltration with a capacity of $15 \mathrm{~m}^{3}$ per hour (Al Naqib 2019). The operating time of the system is 20 hours per day, which yields 300,000 liters of water per system and day (THW 2012a). The treated water meets the drinking water quality standards of the drinking water ordinance (BRD 2018).

Furthermore, we define the following location criteria (Table 4):

According to EPA (2011), an emergency response site should have an area of more than $60 \times 60 \mathrm{~m}$ in size, which is also used as criterion for the needed water system operating area. The locations must be accessible by road to enable deployment and transportation to and 
Table 5 Daily costs for operating one mobile water treatment system

\begin{tabular}{llllll}
\hline Cost driver & Expenses & & Quantity & Sum & Source \\
\hline $\begin{array}{l}\text { Personal costs } \\
\text { Volunteer THW }\end{array}$ & $22.00 €$ & per hour & 18 & $7920.00 €$ & THW (2012b) \\
Equipment costs & & & & & \\
Pumps & $35.00 €$ & per day & 4 & $140.00 €$ & THW (2012b) \\
Power Generator & $4.77 €$ & per hour & 1 & $95.40 €$ & THW (2012b) \\
Water Tanks & $7.70 €$ & per day & 12 & $92.40 €$ & THW (2012b) \\
Drinking Water Laboratory & $18.20 €$ & per day & 1 & $18.20 €$ & THW (2012b) \\
UF-15 & $884.00 €$ & per day & 1 & $884.00 €$ & THW (2012b) \\
Sum & & & & $9150.00 €$ & \\
\hline
\end{tabular}

from the site. Since the water treatment system is also used as a distribution station, locations should be close to demand points (EPA 2011).

The location should also have access to a raw water source (Corsten and Gössinger 2016), which can provide a water feed of $15 \mathrm{~m}^{3}$ per hour. The usage of a maximum of one pump per water treatment system is assumed. It can generate the required flow rate up to the distance of $1200 \mathrm{~m}$. The available number of pumps and their pump capacities separates locations into locations that can be supplied by pump only and locations that must be supplied with additional measures. These measures include supplying raw water by tank truck to site. In the supplementary material, we determined that we need two trucks to supply one treatment system. The THW has 14 trucks with the needed capacities, limiting the operable number of water source distant treatment systems to seven.

The criteria described above were used to process data provided by Berlin's Geoportal (Umweltatlas Berlin 2019a). The identified location candidates are separated into two sets: the first set is within a distance of $1200 \mathrm{~m}$ to a water source and can be supplied by one water pump, while locations in the second set need additional measures to be feasible candidates. The set of locations that can be supplied with a pump contains 2403 locations. The set that contains the locations that need alternative supply measures contain of 157 additional locations.

Table 5 highlights the estimated expenses per day for the operation of an UF-15 system. The estimation includes personal and equipment costs. The total daily operating costs are around $9200 €$ per system if it is placed next to a water source. If tank trucks have to be deployed, the costs increase to $10,300 €$ due to additional personal costs as well as costs for the trucks and fuel. For a detailed overview of the data collection and processing see the supplementary material.

\subsubsection{Supply route}

We define the distance between supply and demand points as supply route. This supply route represents the service standard and is used to select locations for water treatment systems. Within the case study, supply routes between interacting points are calculated using the Euclidean distance. However, the assumption of direct links is not applicable when con- 
sidering overland routes. Therefore, a tortuosity factor of $\sqrt{2}$ is introduced to embrace real road conditions (Delivand 2011; Diehlmann et al. 2019).

According to Langenbach and Fischer (2008), reasonable supply routes in the context of emergency water wells are between 500 and $2000 \mathrm{~m}$. We assume this also applies for the supply with water treatment systems. Therefore, the maximum service standard is examined for a supply route of $1250 \mathrm{~m}$, evaluating an intermediate scenario. A sensitivity analysis for different supply routes lengths follows in the Sect. 6.

\subsubsection{Data summary}

Table 6 provides an overview of the collected data for the case study. It includes the parameter settings for the optimization runs. As already mentioned, the collection and processing of the used data can be found in the supplementary material.

\section{Results}

This chapter summarizes the results of the optimization. The optimization model is implemented in GAMS and solved with the CPLEX-solver. ${ }^{1}$

\subsection{Computation of model input parameters}

Figure 3 provides an overview of the water demand per planning area of the city of Berlin. The darker the shade of the planning areas or the larger the circles, the higher the demand in the area. The figure highlights that special care facilities are often placed within the city center, while the general demand is distributed rather equally within the city.

Moreover, we identified 2560 potential locations to place mobile water treatment systems. Of these possible locations, 2403 are near $(<2 \mathrm{~km})$ a water source, so that a water treatment system can directly be supplied. In Fig. 4, these areas are highlighted (green). In addition, there are 157 potential locations that require supplies by tank trucks (red).

\subsection{Location analysis}

\subsubsection{Optimal locations that maximize covering}

Figure 5 displays the results of the single objective model with the parameters and input data stated above. The regular demand points as well as special demand points in central areas with a high population density are mostly covered. This is a result of the high number of emergency water wells in this area. Without additional water treatment systems they cover a total demand of $77 \%$.

The treatment systems are placed in the outer districts of Spandau, Pankow, Reinickendorf, and Marzahn-Hellersdorf, where the number of emergency wells is lower. All 14 available water treatment systems are placed within close distance to an adequate water source. The systems increase the demand covered by seven percentage points leading to a coverage of $84 \%$ of the total demand.

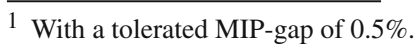


Table 6 Overview of relevant input data for the optimization model

\begin{tabular}{|c|c|c|}
\hline Parameter & Value & Source \\
\hline \multicolumn{3}{|l|}{ Optimization parameters } \\
\hline Distance to water $(d W)$ & $1200 \mathrm{~m}$ & Feuerwehrschulen (2018) \\
\hline $\begin{array}{l}\text { Desired maximum distance } \\
\text { between supply and demand } \\
(S)\end{array}$ & $1250 \mathrm{~m}$ & Fischer and Wienand (2013) \\
\hline $\begin{array}{l}\text { Number of available water } \\
\text { treatment systems (UF-15 } \\
\text { units) }(p)\end{array}$ & 14 & Email exchange with THW \\
\hline $\begin{array}{l}\text { Maximum number of water } \\
\text { treatment systems that can be } \\
\text { supplied by trucks }(q)\end{array}$ & 7 & $\begin{array}{l}\text { Wisetjindawat et al. (2014), } \\
\text { Email exchange with fire } \\
\text { brigade Berlin and THW }\end{array}$ \\
\hline $\begin{array}{l}\text { Minimum percent of demand } \\
\text { supplied per trip }(f)\end{array}$ & $20 \%$ & $\begin{array}{l}\text { Sphere Project (2018) } \\
\text { BRD (1970) }\end{array}$ \\
\hline $\begin{array}{l}\text { Operating Costs Water } \\
\text { emergency wells }(\operatorname{cost} E W)\end{array}$ & $10,700 €$ per day & THW (2012b), Träger (2019) \\
\hline $\begin{array}{l}\text { Operating Costs Water } \\
\text { Treatment Systems }(\cos t L W)\end{array}$ & $9200 €$ per day & THW (2012b) \\
\hline $\begin{array}{l}\text { Operating Costs Water } \\
\text { Treatment Systems further } \\
\text { away from water source } \\
(\text { cost } L C)\end{array}$ & $10,300 €$ per day & $\begin{array}{l}\text { THW (2012b), Statistisches } \\
\text { Bundesamt (2019) }\end{array}$ \\
\hline \multicolumn{3}{|l|}{ Spatial demand structure } \\
\hline $\begin{array}{l}\text { Number of regular demand } \\
\text { points }\end{array}$ & 14,755 & $\begin{array}{l}\text { Amt für Statistik } \\
\text { Berlin-Brandenburg (2019a) }\end{array}$ \\
\hline $\begin{array}{l}\text { Number of special demand } \\
\text { points (hospitals, nursing } \\
\text { homes, sheltered housing) }\end{array}$ & 529 & $\begin{array}{l}\text { Berliner } \\
\text { Krankenhausgesellschaft } \\
\text { (2019), Privatinstitut für } \\
\text { Transparenz im } \\
\text { Gesundheitswesen (2019) }\end{array}$ \\
\hline
\end{tabular}

Emergency Wells

Number of operated emergency 1028

Geofabrik (2019) water wells $(F T)$

Daily drinking water supply $\left(c_{j}\right)$

90,000 liters per well Fischer and Wienand (2013)

Mobile water treatment systems

Location candidates next to

EPA (2011), Corsten and Gössinger (2016), Fischer and Wienand (2013),

Feuerwehrschulen (2018), Umweltatlas Berlin (2019b) 
Table 6 continued

\begin{tabular}{|c|c|c|}
\hline Parameter & Value & Source \\
\hline $\begin{array}{l}\text { Location candidates that must } \\
\text { be supplied by trucks }(D W T)\end{array}$ & 157 & $\begin{array}{l}\text { Wisetjindawat et al. (2014), } \\
\text { email exchange fire brigade } \\
\text { Berlin, email exchange THW }\end{array}$ \\
\hline $\begin{array}{l}\text { Daily drinking water supply } \\
\left(c_{j}\right)\end{array}$ & 300,000 liters per system & THW (2012a) \\
\hline \multicolumn{3}{|l|}{ Distance } \\
\hline Distance Calculation & Euclidean Distance & Mwemezi and Huang (2011) \\
\hline Tortuosity factor & $\operatorname{sqrt}(2)$ & Diehlmann et al. (2019) \\
\hline
\end{tabular}

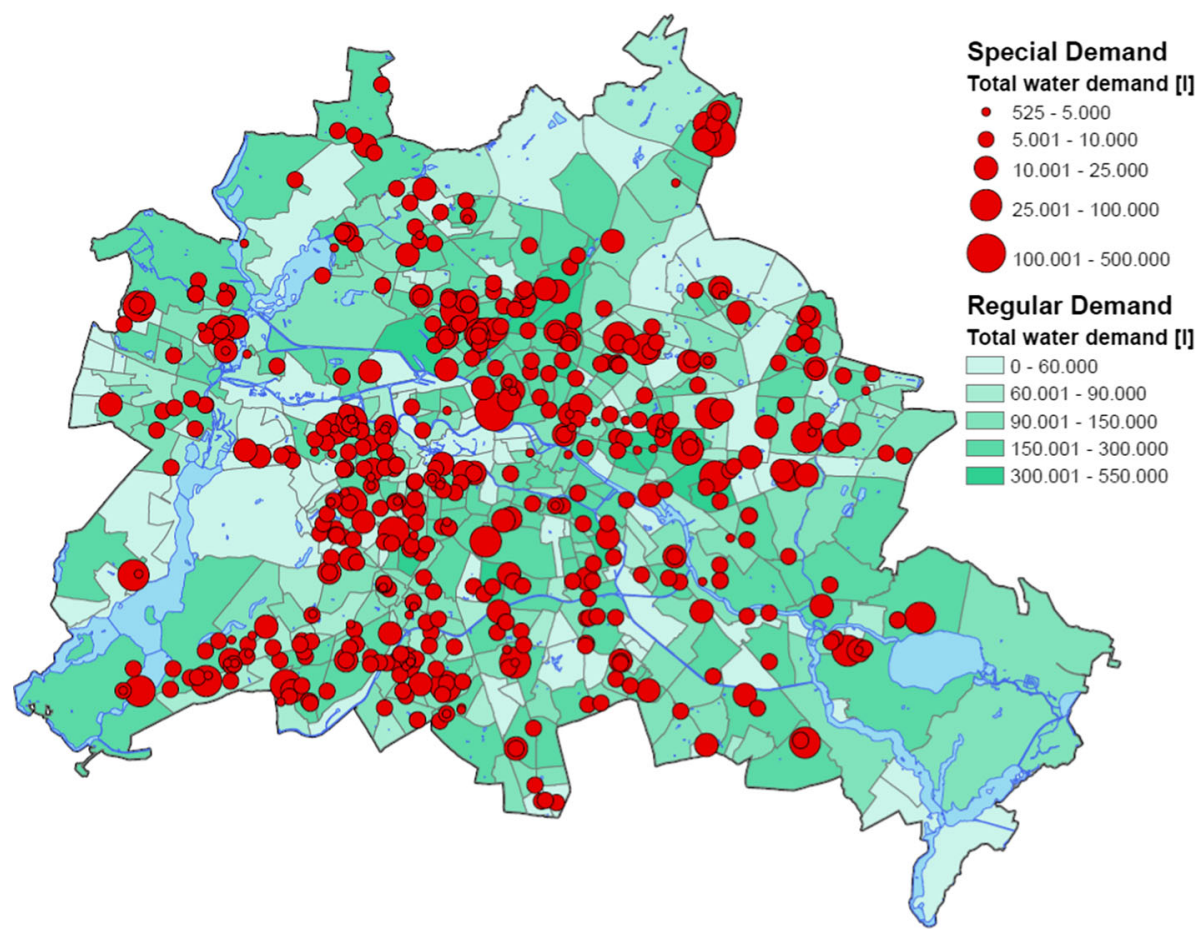

Fig. 3 Map of water demand of regular residents and high care facilities in the city of Berlin. The demand of the residents is aggregated to planning areas of the city. The different colors represent the total water demand in liters [1]

The total costs associated with the emergency response are $11,128,400 €$ per day resulting from operating the 1028 emergency water wells and 14 water treatment systems. These high costs indicate the need of a multi-criteria optimization approach including a cost criterion. 


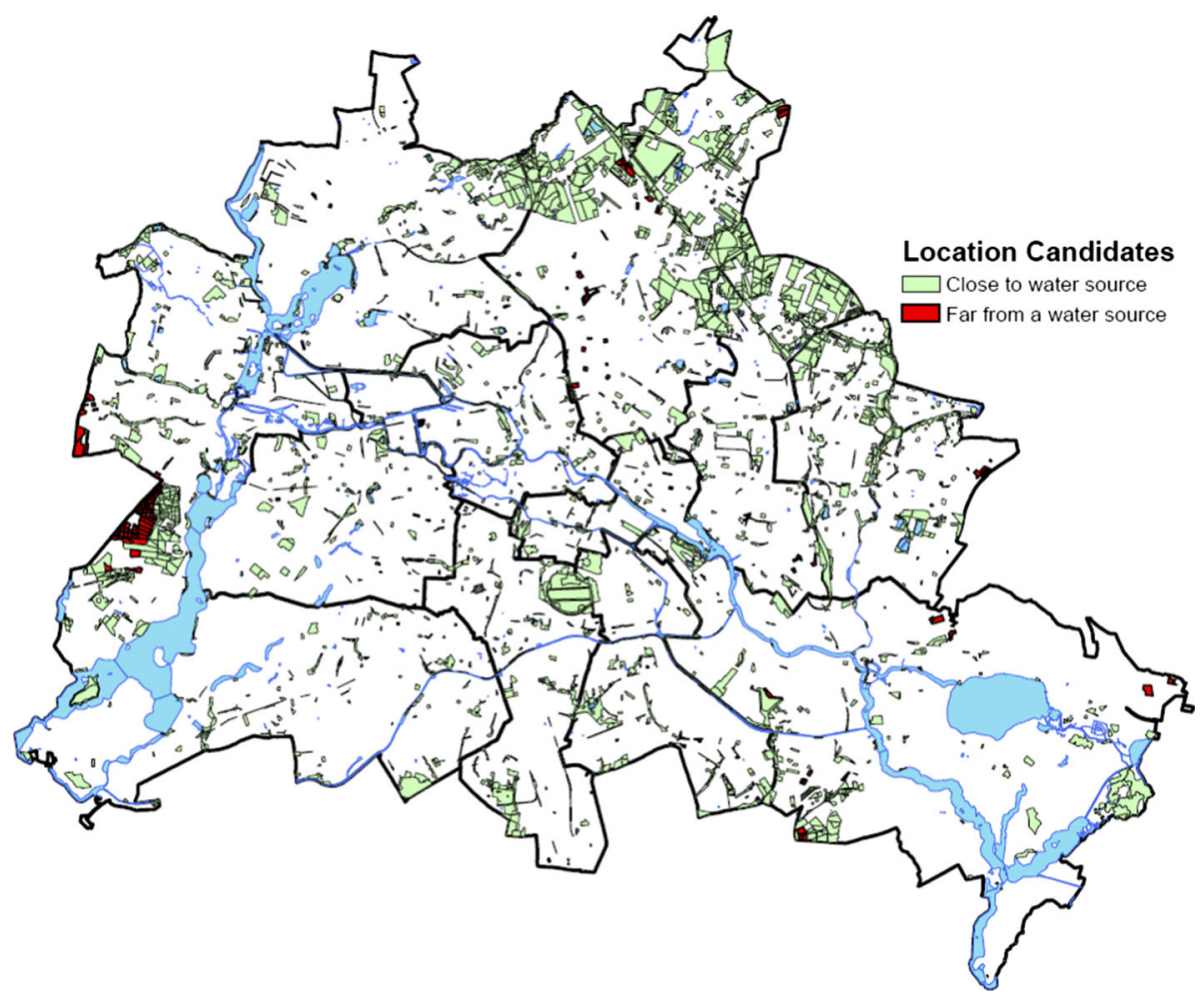

Fig. 4 Map of location candidates for placing water treatment systems in the city of Berlin. The locations are distinguished according to their distance to the closest water source

\subsubsection{Optimal locations for cost-efficient maximum covering}

A cost-efficient emergency supply enables the investment of saved resources in other areas of the emergency response.

The results of the proposed lexicographic two-step approach are comparable to the results of the single objective model with a coverage of $84 \%$. Because other locations in the outer districts of Spandau, Pankow, Reinickendorf, and Marzahn-Hellersdorf have been chosen, the solution space for the optimal coverage does not seem to be bijective. However, within the solution space, no solution is more cost-efficient than the one found with the single objective model. Therefore, the total costs associated with the lexicographic optimization are also $11,128,400 €$ per day. The high operation costs are caused by the emergency water wells and the assumption that all are operated. These fix costs amount to a rounded 11,000,000€ and cannot be influenced by the model design and decision variables.

\subsubsection{Prioritization of special demand over regular demand}

As mentioned above, decision makers try to prioritize the highly vulnerable demand points in disaster relief. To investigate the effects of such a prioritization of demand types, the lexicographic CMLCP is slightly modified: the gradual optimization of coverage and costs 


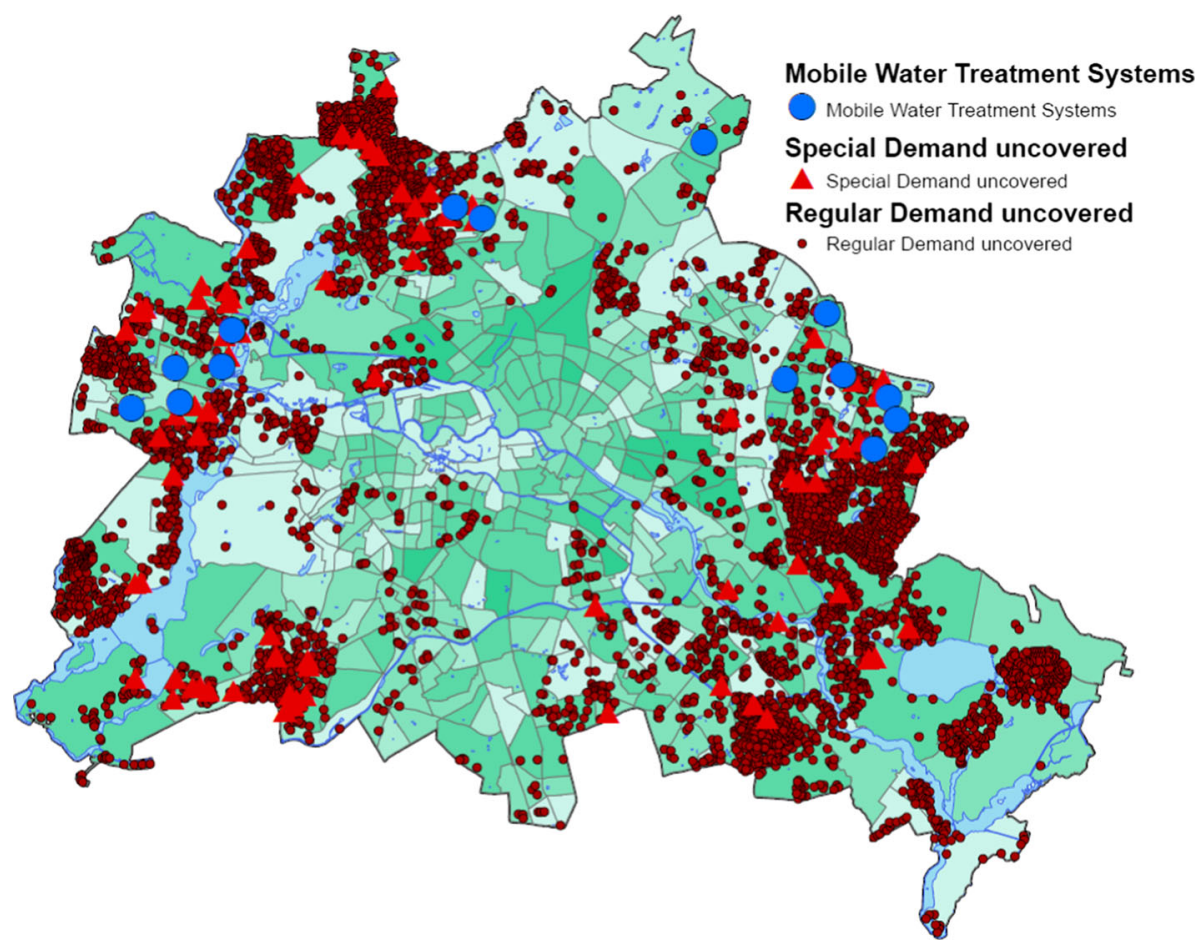

Fig. 5 Map of regular and special demand points left uncovered, considering a maximum supply route of 1250 $\mathrm{m}$

is replaced by the gradual optimization of special and regular demand covered. Therefore, the objective function of the CMCLP is split into covering high care facilities and covering regular demand points. The model assumes that the decision maker prioritizes the demand of high care facilities. Therefore, the objectives are optimized in this order.

The result of the modified lexicographic approach is a total coverage of $81 \%$ covering $91 \%$ of the demand of high care facilities and $80 \%$ of the regular demand. The costs are $11,129,500 €$ resulting from operating 1028 emergency water wells, 13 water treatment systems close to a water source and one water treatment system that has to be supplied by truck. The map shows that some of the mobile systems are placed in more central districts like Mitte, Friedrichshain, Charlottenburg, Tempelhof, and Steglitz (see Fig. 6). This emphasizes the prioritization of the special demand in this area, as high care facilities that were only partially supplied are now being fully supplied.

\section{Discussion}

This section discusses the generated results and highlights trade-offs between different objectives. The design and assumptions of the model are also critically reviewed. 


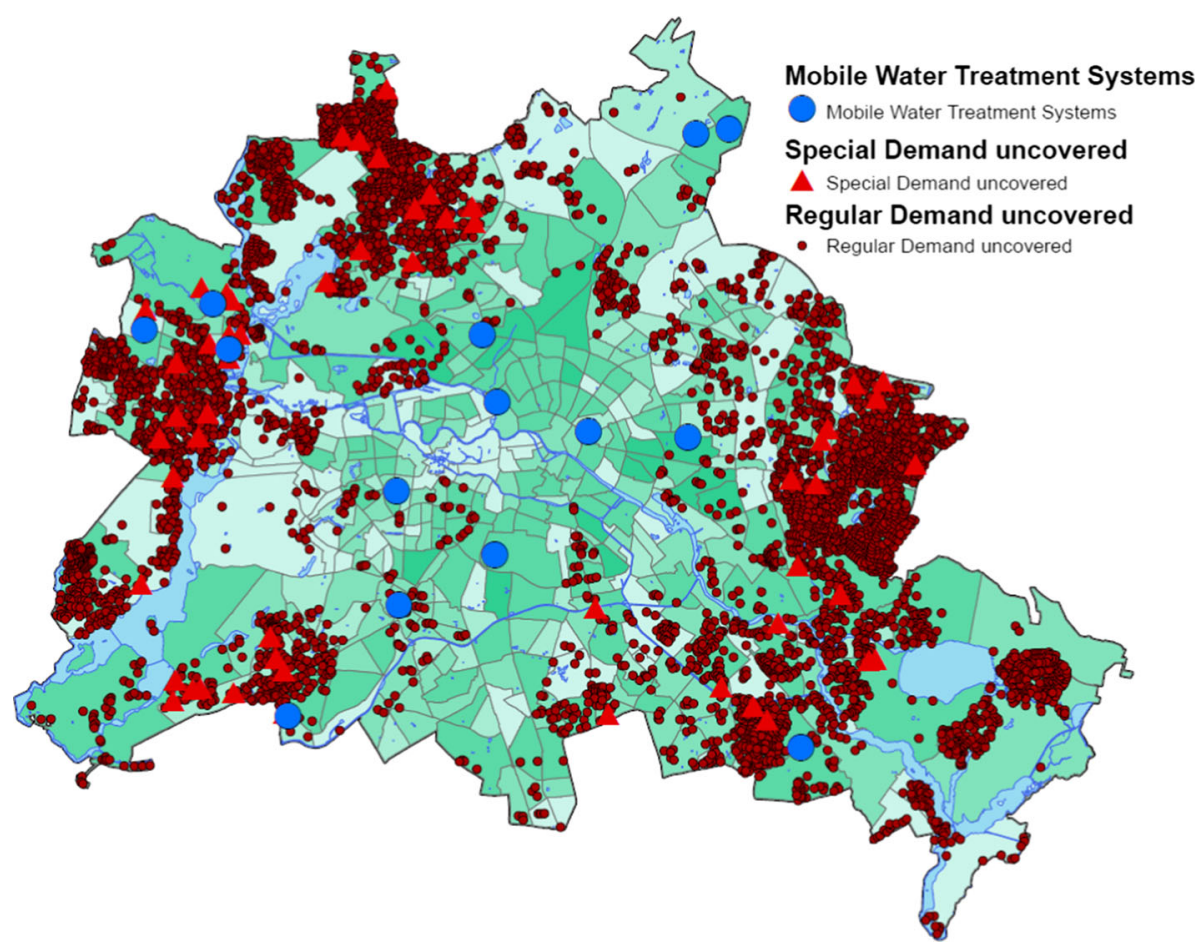

Fig. 6 Map of locations of mobile water treatment systems placed when prioritizing high care facilities

\subsection{Length of the supply route}

The maximum length of the supply route impacts the total demand coverage (Fig. 7). In the diagram, the length of the supply route ranges between 500 and $2000 \mathrm{~m}$ (as suggested by Langenbach and Fischer 2008). While shorter supply routes decrease the travel distance of a supplied person, longer maximal supply routes increase the total coverage.

The results show that a short maximum supply route leads to a considerably low coverage of $63 \%$. The coverage increases by 12 percentage points when the maximal length allowed is set to $750 \mathrm{~m}$. Within the defined value range, the maximal total coverage is $88 \%$.

As coverage is strongly influenced by the supply route, a short supply route reduces the chance that demand can be allocated to a facility within the defined maximum length of the supply route. However, we can also see that prolonging the supply route from 1250 to $2000 \mathrm{~m}$ only gains $4 \%$ additional coverage. Thus, the decision maker has to determine a reasonable length for the supply routes.

Within this paper, the distance is determined by the linear distance between two points and a tortuosity factor. Thus, the distance between supply and demand is only an approximation. Determining the distance based on a network length could increase the accuracy of the results.

\subsection{Number of water treatment systems to ensure a specific coverage}

To increase the supply, it is possible to purchase additional purification systems at additional cost. Therefore, we analyzed the number of necessary systems to provide predefined coverage 


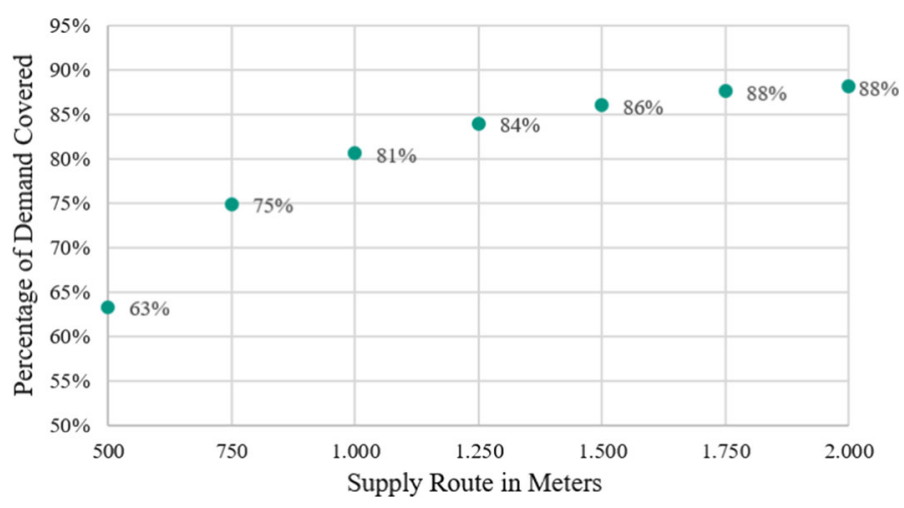

Fig. 7 Achievable coverage dependent on the maximum length of the supply route

with the help of a capacitated location set covering problem (CLSCP). The optimal and capacitated version of the prototypical LSCP is described by Church and Murray (2019). The introduced notation is extended by the parameter perTotalCov introduced in Table 2, which determines the percentage of the total water demand that must be covered.

The CLSCP is locating the minimum number of facilities needed so that the defined coverage can be reached (Church and Murray 2019). Thus, the objective function 19 minimizes the number of placed facilities. Compared to the prototypical formulation by Church and Murray (2019), total demand must not be fully covered in our case since total coverage only has to be higher than a predefined percentage described by constraint 20 . Therefore, not every demand point must be covered within the service standard (21). The other constraints are equal to the constraints formulated for the CMCLP. Therefore, they are not further discussed.

$$
\begin{array}{cl}
\text { minimize } & \sum_{i \in W T} x_{j} \\
\text { subject to } \sum_{i \in I} \sum_{j \in N_{i}} z_{i j} * a_{i} \geq \operatorname{perTotalCov} * \sum_{i \in I} a_{i}, \\
z_{i j} \geq y_{i j} * f, & \forall i \in I, \\
\sum_{i \in K_{j}} a_{i} * z_{i j} \leq c_{j} * x_{j}, & \forall i \in I, \forall j \in N_{i}, \\
\sum_{j \in J} s_{j w} \leq c_{w}, & \forall j \in J, \\
\sum_{w \in W} s_{j w} \leq 1, & \forall w \in W S, \\
\sum_{w \in W S} s_{j w} \leq a l_{j w}, & \forall j \in J, \\
z_{i j} \leq x_{j}, & \forall j \in J, \forall w \in W S,
\end{array}
$$




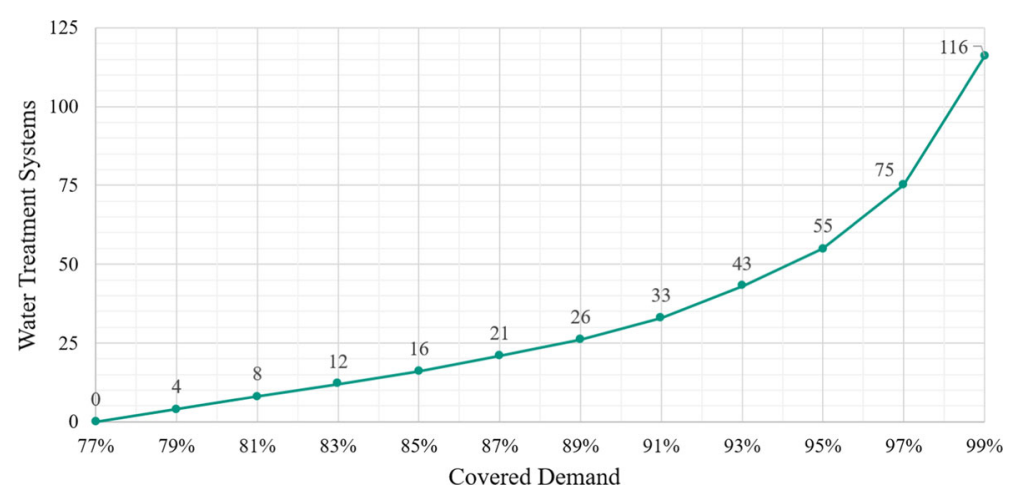

Fig. 8 Number of water treatment systems required to reach a targeted coverage

$$
\begin{array}{ll}
y_{i j} \geq z_{i j}, & \forall i \in I, \forall j \in J, \\
y_{i j} \leq z_{i j} * M, & \forall i \in I, \forall j \in J, \\
x_{j} \in\{0,1\}, & \forall j \in J, \\
y_{i j} \in\{0,1\}, & \forall i \in I, \forall j \in J, \\
z_{i j} \geq 0, & \forall j \in J .
\end{array}
$$

Since the introduced CLSCP determines the required number of water treatment systems to reach a predefined percentage of total coverage, the relationship between both is analyzed. The nonlinear trade-off curve shows that there is no feasible solution for full coverage while considering only the identified locations to place the mobile treatment systems (Fig. 8).

The maximal possible coverage is $99 \%$ with 116 required water treatment systems. The existing infrastructure of emergency water wells is covering $77 \%$ of the total demand. A high number of water treatment systems is needed to yield a significant increase in coverage.

In the case study, only 14 systems are available increasing the coverage to $84 \%$. The purchase and deployment of additional water treatment systems for the THW is therefore an option to increase the demand coverage. However, a small number of additional systems would only lead to a small increase of coverage. Moreover, the decision makers have to decide if an increase in coverage is worth the associated costs or if the money could be spend more efficient in other ways.

Reasons why full coverage cannot be achieved may result from data quality and data preparation. Moreover, it is possible that individual persons cannot be reached within the approved lengths for the supply route. This could include, for example, the inhabitants of the islands in Lake Tegel, as they are isolated.

Figure 8 also indicates the importance of the existing emergency wells, which can be accessed easily. Eliminating the capacities of the wells results in a coverage of $7 \%$ deploying the currently available 14 water treatment systems. The highest possible coverage without wells is $99 \%$. 1,596 mobile treatment systems with an average utilization rate of $7 \%$ are required.

This demonstrates the importance of the existing emergency water wells. Mobile water treatment systems are not suitable to reach full coverage by themselves and the existing network of emergency wells should be extended. 


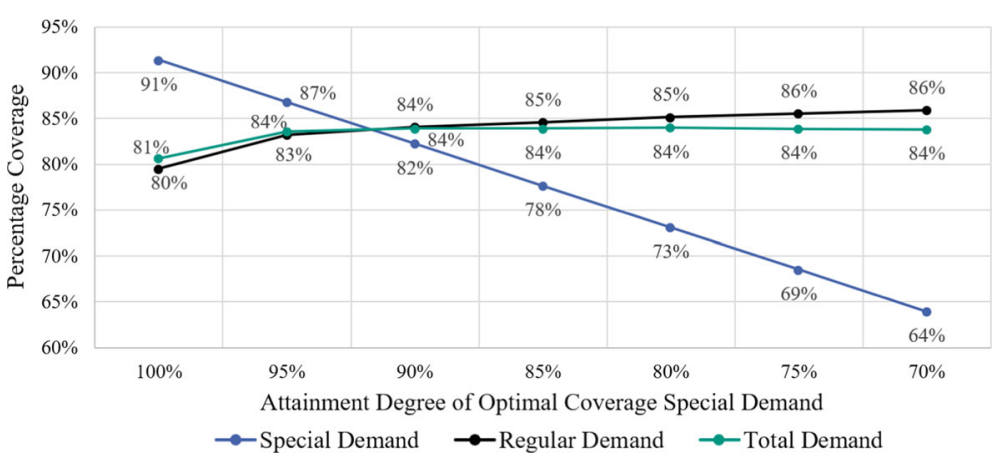

Fig. 9 Trade-off between coverage of high care facilities and coverage of regular residents

\subsection{Relaxation of constraints for the prioritization of special demand}

The objective attainment degree allows a deviation from the optimal solution to investigate the possible trade-off between coverage of special and regular demand. This degree defines the minimum value of the optimal solution that must be reached. The attainment degree of $100 \%$ yields an optimal coverage for the special demand of $91 \%$. For this solution, the regular demand covered is $80 \%$ resulting in a total coverage of $81 \%$. By lowering the attainment degree, it is possible to cover more regular demand points (Fig. 9).

We see that the total coverage varies little within the analysis. The optimal total coverage of $84 \%$ is reached with an attainment degree of $95 \%$. With this attainment degree, $87 \%$ of the special demand and $83 \%$ of the regular demand is covered. The coverage of the regular demand is close to its possible maximum of $86 \%$.

The results show that the impact of the special demand on the total coverage is smaller than the impact of the regular demand. This results from the lower total demand at high care facilities, which account for $10 \%$ of the total demand. The optimum coverage of the total demand decreases only slightly when high care facilities are prioritized. The decision maker has to decide if the prioritization is worth this difference.

\subsection{Trade-off between coverage and costs}

In the following Subsection, we analyze the trade-off between coverage and costs. However, we want to point out that this does not hint that authorities would not try to supply as many people as possible. A reduction of cost could also mean that authorities make resources available for other measures that support the population as well. For example, authorities could increase the total supply to the population if a comparably small loss in coverage by the treatment systems saves enough money to purchase a truck full of bottled water. Even though it can be discussed that Berlin's authorities could count on more or less unlimited financial support of the state in such a severe disaster, this probably does not apply to some authorities in developing countries or Non-Governmental-Organizations (NGOs) working on a budget.

The trade-off curve between optimum coverage and flexible daily costs shows that a deviation from the optimal coverage enables potential cost savings (Fig. 10). The flexible daily costs associated with the optimal coverage are $128,800 €$ (14 mobile purification systems $* 9200 €$ per day). 


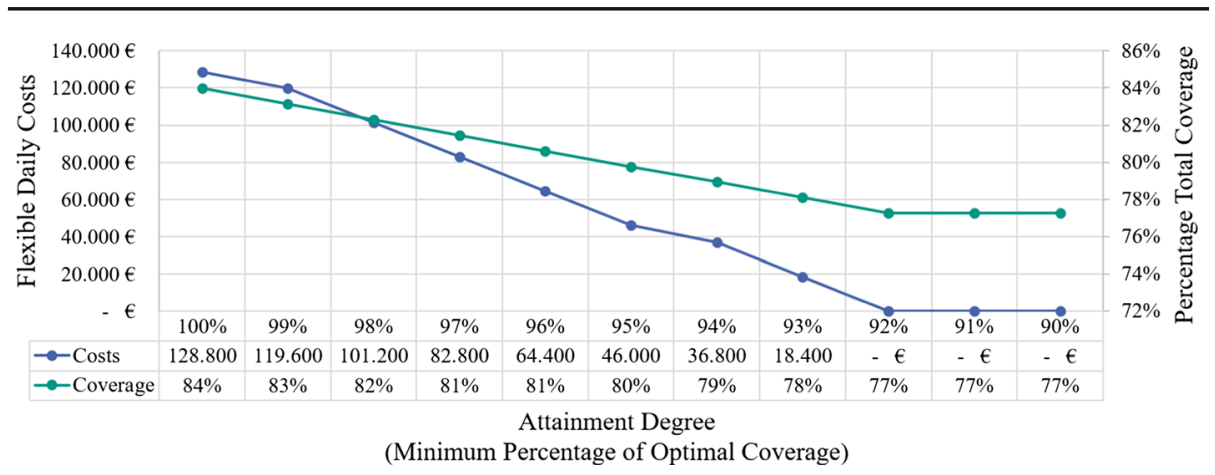

Fig. 10 Trade-off between cost and coverage displayed based on the attainment degree of the solution for optimal coverage

The reduction of the attainment degree to $99 \%$ leads to cost savings of $9200 €$ while $83 \%$ of the total demand is covered. Further reduction of the attainment degree leads to a linear decrease of the daily costs. This trend is interrupted between the attainment degree of $95 \%$ and $94 \%$ before continuing linearly after $94 \%$. With the reduction of the attainment degree below $93 \%$ no water treatment systems are placed, and water is only provided with the existing emergency infrastructure.

In the linear parts of the trade-off curve, the decision maker has to decide whether cost savings of $18,400 €$ are worth it to lose 522,414 liters of water, which could supply more than 34,000 residents. The trade-off curve, therefore, provides the decision maker with a higher transparency regarding the consequences of his or her decision. Consequently, he or she can derive more efficient and well-informed decisions on the deployment of water treatment systems, and use the available budget as efficient as possible.

\section{Conclusion and research outlook}

The design of an emergency water distribution system represents a difficult challenge for authorities. A variety of trade-offs has to be regarded for an efficient solution. To support public decision makers in this process, we developed a capacitated maximal covering location model based on georeferenced data that maximizes the water demand covered, followed by a cost minimization step.

We applied the approach to a case study in the city of Berlin, Germany. Therefore, we extended the model with a multi-objective approach to regard various trade-offs. For example, we showed that a prioritization of special demand suggests completely different locations for the mobile treatment systems. Moreover, we increased cost transparency by the investigation of the trade-off between cost and coverage. This enables the decision maker to know the effective price (or opportunity cost respectively) of additional water supply facilities in an emergency.

It can be concluded that the deployment of mobile water treatment systems extending existing infrastructure increases the covered water demand and the supply of suffering people significantly. Thereby, a high spatial density of existing emergency infrastructure is the basis for a high coverage within reasonable supply routes. In Berlin, this is demonstrated by a close network of wells within the city center, already covering $77 \%$ of the total demand. The deployment of additional 14 mobile water treatment systems increased the total demand 
covered by only seven percentage points to $84 \%$ of the total demand. Furthermore, a supply based on mobile water treatment systems alone resulted in a total coverage of $7 \%$. Mobile systems are associated with additional costs, leading to the key trade-off between coverage and costs.

However, the case study did not regard uncertainties like the functionality of a well or the availability of treatment systems. Even though legal maintenance procedures both on water treatment systems and emergency wells are implemented, there is still a risk of water treatment system or well failure. Therefore, the effects of possible malfunction could be analyzed a priori with the help of a Monte Carlo Simulation or two-stage stochastic programming in a follow-up study or could be covered posteriori by another model run with respectively updated data. Moreover, it is reasonable to expect a significant time delay between the start of the crisis and the availability of all treatment systems. Therefore, a stochastic or dynamic extension of the model could provide valuable information.

Another extension could be to take the geographic distribution of stockpiled water into consideration and locate the adjusted demand. One example could be that people with larger apartments are more likely to store water at home than people with small apartments (Bell and Hilber 2006). Integrating the adjusted demand into the developed model consisting of wells and mobile water treatment systems might further increase the applicability to the real world. Furthermore, the adjusted demand might lead to higher coverage rates.

In addition, most of the used data is publicly available. Therefore, the data (and cost data in particular) could be further validated by experts and adjusted to the way costs are invoiced or distributed in disaster management practice. Requests to validate the cost estimations led to the surprising situation that different organizations and authorities could not provide us with real data, but instead, reciprocally referred to each other. This hints towards a general cost-transparency problem, which could be addressed in future studies.

In spite of the aforementioned challenges, the approach has the potential to significantly increase the transparency of decisions for decision makers and therefore improve the efficiency of disaster relief management.

Acknowledgements This research was supported by the German Federal Ministry of Education and Research (BMBF) in the NOLAN project (Grant Number: 13N14457). Furthermore, we want to thank the employees at diverse disaster management authorities for their support during the data collection and validation process and also the anonymous reviewers for their valuable feedback. Moreover, we acknowledge support by the KIT-Publication Fund of the Karlsruhe Institute of Technology.

Funding Open Access funding enabled and organized by Projekt DEAL.

\section{Compliance with ethical standards}

Conflict of interest The authors declare that they have no conflict of interest.

Open Access This article is licensed under a Creative Commons Attribution 4.0 International License, which permits use, sharing, adaptation, distribution and reproduction in any medium or format, as long as you give appropriate credit to the original author(s) and the source, provide a link to the Creative Commons licence, and indicate if changes were made. The images or other third party material in this article are included in the article's Creative Commons licence, unless indicated otherwise in a credit line to the material. If material is not included in the article's Creative Commons licence and your intended use is not permitted by statutory regulation or exceeds the permitted use, you will need to obtain permission directly from the copyright holder. To view a copy of this licence, visit http://creativecommons.org/licenses/by/4.0/. 


\section{References}

Al Naqib, B. (2019). Technische Hilfe in Katastrophen- und Krisenfall: Trinkwasserversorgung. https:// docplayer.org/docview/62/46737109/\#file=/storage/62/46737109/46737109.pdf. Accessed 17 June 2020.

Al-Weshah, R. A., \& Yihdego, Y. (2018). Multi-criteria decision approach for evaluation, ranking, and selection of remediation options: Case of polluted groundwater, kuwait. Environmental Science and Pollution Research International, 25(36), 36039-36045.

Amt für Statistik Berlin-Brandenburg. (2018). Flächennutzung Berlin. https://www.statistik-berlinbrandenburg.de/regionalstatistiken/r-gesamt_neu.asp?Ptyp=410\&Sageb=33000\&creg=BBB \& anzwer=8. Accessed 17 June 2020.

Amt für Statistik Berlin-Brandenburg. (2019a). Einwohnerdichte 2018 (Umweltatlas). https://fbinter.stadtberlin.de/fb/index.jsp. Accessed 17 June 2020.

Amt für Statistik Berlin-Brandenburg. (2019b). Einwohnerinnen und Einwohner in Berlin in LOR-Planungsräumen. https://daten.berlin.de/datensaetze/einwohnerinnen-und-einwohner-berlin-lorplanungsr\%E4umen-am-31122018. Accessed 17 June 2020.

Barbarosoğlu, G., Özdamar, L., \& Çevik, A. (2002). An interactive approach for hierarchical analysis of helicopter logistics in disaster relief operations. European Journal of Operational Research, 140(1), $118-133$.

Bastian, N. D., Griffin, P. M., Spero, E., \& Fulton, L. V. (2016). Multi-criteria logistics modeling for military humanitarian assistance and disaster relief aerial delivery operations. Optimization Letters, 10(5), 921953.

BBK. (2016a). Sicherheit der Trinkwasserversorgung: Grundlagen und Handlungsempfehlungen für Aufgabenträger der Wasserversorgung in den Kommunen in Bezug auf außergewöhnliche Gefahrenlagen: Teil 1: Risikoanalyse. Bundesamt für Bevölkerungsschutz und Katastrophenhilfe (BBK). https://www.bbk.bund.de/SharedDocs/Downloads/Kritis/DE/Band-15_Praxis_BS_ Trinkwasserversorgung.pdf?_blob=publicationFile. Accessed 17 June 2020.

BBK. (2016b). Sicherheit der Trinkwasserversorgung: Grundlagen und Handlungsempfehlungen für Aufgabenträger der Wasserversorgung in den Kommunen in Bezug auf außergewöhnliche Gefahrenlagen: Teil 2: Notfallversorgung. Bundesamt für Bevölkerungsschutz und Katastrophenhilfe (BBK). https://www.bbk.bund.de/SharedDocs/Downloads/Kritis/DE/Band-15_Praxis_BS_ Trinkwasserversorgung.pdf?_blob=publicationFile. Accessed 17 June 2020.

Bell, D. R., \& Hilber, C. A. L. (2006). An empirical test of the Theory of Sales: Do household storage constraints affect consumer and store behavior? Quantitative Marketing and Economics, 4(2), 87-117.

Bennett, V. L., Eaton, D. J., \& Church, R. L. (1982). Selecting sites for rural health workers. Social Science \& Medicine, 16(1), 63-72.

Berliner Krankenhausgesellschaft e.V. (2019). Berliner Krankenhaus Verzeichnis. https://www.berlinerkrankenhausverzeichnis.de/. Accessed 17 June 2020.

Berliner Wasserbetriebe. (2019). Wasser im Haushalt. https://www.bwb.de/de/523.php. Accessed 17 June 2020.

BMI. (2009). National strategy for critical infrastructure protection. German Federal Ministry of the Interior (BMI). https://www.bmi.bund.de/SharedDocs/downloads/EN/publikationen/2009/kritis_englisch. pdf?_blob=publicationFile\&v=1. Accessed 17 June 2020.

Boehme, K., Geißler, S., \& Schweer, B. (2012). Szenario eines großflächigen und lang anhaltenden Stromausfalls in Berlin: BMBF- Projekt TankNotStrom. https://opus4.kobv.de/opus4-hwr/files/413/ Szenario+Berlin_2012.11.21.pdf. Accessed 17 June 2020.

Boonmee, C., Arimura, M., \& Asada, T. (2017). Facility location optimization model for emergency humanitarian logistics. International Journal of Disaster Risk Reduction, 24, 485-498.

BRD. (1970). Erste Wassersicherstellungsverordnung: 1. WasSV. Bundesrepublik Deutschland (BRD). https:// www.gesetze-im-internet.de/wassv_1/BJNR003570970.html. Accessed 17 June 2020.

BRD. (2018). Verordnung über die Qualität von Wasser für den menschlichen Gebrauch (Trinkwasserverordnung-TWV). Bundesrepublik Deutschland (BRD). https://www.gesetze-iminternet.de/trinkwv_2001/BJNR095910001.html. Accessed 17 June 2020.

Bross, L., Krause, S., Wannewitz, M., Stock, E., Sandholz, S., \& Wienand, I. (2019). Insecure security: Emergency water supply and minimum standards in countries with a high supply reliability. Water, 11(4), 732.

Chung, C., Schilling, D., \& Carbone, R. (1983). The capacitated maximal covering problem: A heuristic. In Proceedings of Fourteenth Annual Pittsburgh Conference on Modeling and Simulation (pp. 1423-1428).

Church, R., \& Murray, A. (2019). Location covering models: History, applications and advancements. Advances in spatial science. Cham, Suisse: Springer. 
Church, R., \& ReVelle, C. (1974). The maximal covering location problem. Papers of the Regional Science Association, 32, 101-118.

Clasen, T., \& Boisson, S. (2006). Household-based ceramic water filters for the treatment of drinking water in disaster response: an assessment of a pilot programme in the Dominican Republic. Water Practice and Technology. https://doi.org/10.2166/wpt.2006.031.

Clasen, T., Smith, L., Albert, J., Bastable, A., \& Fesselet, J.-F. (2006). The drinking water response to the indian ocean tsunami, including the role of household water treatment. Disaster Prevention and Management: An International Journal, 15(1), 190-201.

Corsten, H., \& Gössinger, R. (2016). Produktionswirtschaft: Einführung in das industrielle Produktionsmanagement / Hans Corsten. De Gruyter Oldenbourg: Ralf Gössinger.

Current, J., \& O’Kelly, M. (1992). Locating emergency warning sirens. Decision Sciences, 23(1), 221-234.

Daskin, M. S. (2008). What you should know about location modeling. Naval Research Logistics, 55(4), 283-294.

Davis, C. (2014). Water system service categories, post-earthquake interaction, and restoration strategies. Earthquake Spectra, 30(4), 1487-1509.

Delivand, M. (2011). Assessing the feasibility of process chains for energy production from rice straw in Thailand. Ph.D. Thesis. Dissertation at the Joint Graduate School of Energy and Environment.

Deutscher, Bundestag. (1990). Gesetz über das Technische Hilfswerk (THW-Gesetz - THWG). http://www. gesetze-im-internet.de/thw-helfrg/THWG.pdf. Accessed 17 June 2020.

Diehlmann, F., Zimmer, T., Glöser-Chahoud, S., Wiens, M., \& Schultmann, F. (2019). Techno-economic assessment of utilization pathways for rice straw: A simulation-optimization approach. Journal of Cleaner Production, 230, 1329-1343.

Doerner, K. F., Gutjahr, W. J., \& Nolz, P. C. (2009). Multi-criteria location planning for public facilities in tsunami-prone coastal areas. OR Spectrum, 31(3), 651-678.

Dorea, C. C., Luff, R., Bastable, A., \& Clarke, B. A. (2009). Up-flow clarifier for emergency water treatment. Water and Environment Journal, 23(4), 293-299.

Enqvist, J. P., \& Ziervogel, G. (2019). Water governance and justice in cape town: An overview. Wiley Interdisciplinary Reviews: Water, 149(4), e1354.

EPA. (2011). Planning for an Emergency Drinking Water Supply. https://www.epa.gov/sites/production/files/ 2015-03/documents/planning_for_an_emergency_drinking_water_supply.pdf. Accessed 17 June 2020.

Farahani, R. Z., SteadieSeifi, M., \& Asgari, N. (2010). Multiple criteria facility location problems: A survey. Applied Mathematical Modelling, 34(7), 1689-1709.

Feuerwehrschulen, Bayern. (2018) . Wasserförderung über lange Schlauchstrecken: Merkblatt. https://www. sfs-w.de/downloads.html?no_cache=1\&download=5008_Inhalt_Wasserfoerderung_2018-05-16.pdf\& did=38. Accessed 17 June 2020 .

Fischer, P., \& Wienand, I. (2013). Trinkwassernotbrunnen - wasserversorgung in extremsituationen. https:// www.bbk.bund.de/SharedDocs/Downloads/BBK/DE/Publikationen/PublikationenKritis/notbrunnen_ extremsituation.pdf?_blob=publicationFile. Accessed 17 June 2020.

Garsadi, R., Salim, H. T., Soekarno, I., Doppenberg, A., \& Verberk, J. (2009). Operational experience with a micro hydraulic mobile water treatment plant in indonesia after the "tsunami of 2004". Desalination, 248(1-3), 91-98.

Geofabrik, GmbH. (2019). OpenStreetMap Data in Layered GIS-Format. http://download.geofabrik.de/osmdata-in-gis-formats-free.pdf. Accessed 17 June 2020.

Gigović, L., Pamučar, D., Bajić, Z., \& Drobnjak, S. (2017). Application of gis-interval rough ahp methodology for flood hazard mapping in urban areas. Water, 9(6), 360.

Hiscock, K. M., \& Grischek, T. (2002). Attenuation of groundwater pollution by bank filtration. Journal of Hydrology, 266(3), 139-144.

Holguín-Veras, J., Pérez, N., Jaller, M., van Wassenhove, L. N., \& Aros-Vera, F. (2013). On the appropriate objective function for post-disaster humanitarian logistics models. Journal of Operations Management, 31(5), 262-280.

Hong, J.-D., Xie, Y., \& Jeong, K.-Y. (2012). Development and evaluation of an integrated emergency response facility location model. Journal of Industrial Engineering and Management, 5(1), 4-21.

IASC. (2010). IASC strategy: Meeting humanitarian challenges in urban areas.

IFRC. (2011). The Red Cross Red Crescent approach to disaster and crisis management: Position Paper. https:// www.ifrc.org/PageFiles/91314/1209600-DM-Position-Paper-EN.pdf. Accessed 17 June 2020.

Jain, R. (2012). Providing safe drinking water: A challenge for humanity. Clean Technologies and Environmental Policy, 14(1), 1-4.

Jia, H., Ordóñez, F., \& Dessouky, M. (2007). A modeling framework for facility location of medical services for large-scale emergencies. IIE Transactions, 39(1), 41-55. 
Kwan, M.-P., Murray, A. T., O’ Kelly, M. E., \& Tiefelsdorf, M. (2003). Recent advances in accessibility research: Representation, methodology and applications. Journal of Geographical Systems, 5(1), 129-138.

Langenbach, M., \& Fischer, P. (2008). Trinkwasser- Notbrunnen in Deutschland. bbr - Fachmagazin für Brunnen- und Leitungsbau, 11.

Lantagne, D., \& Clasen, T. (2013). Effective use of household water treatment and safe storage in response to the 2010 haiti earthquake. The American Journal of Tropical Medicine and Hygiene, 89(3), 426-433.

Li, X., Zhao, Z., Zhu, X., \& Wyatt, T. (2011). Covering models and optimization techniques for emergency response facility location and planning: A review. Mathematical Methods of Operations Research, 74(3), 281-310.

Lin, Y.-H., Batta, R., Rogerson, P. A., Blatt, A., \& Flanigan, M. (2012). Location of temporary depots to facilitate relief operations after an earthquake. Socio-Economic Planning Sciences, 46(2), 112-123.

Loo, S.-L., Fane, A. G., Krantz, W. B., \& Lim, T.-T. (2012). Emergency water supply: A review of potential technologies and selection criteria. Water Research, 46(10), 3125-3151.

Loree, N., \& Aros-Vera, F. (2018). Points of distribution location and inventory management model for PostDisaster Humanitarian Logistics. Transportation Research Part E: Logistics and Transportation Review, $116,1-24$.

Mahmood, Q., Baig, S. A., Nawab, B., Shafqat, M. N., Pervez, A., \& Zeb, B. S. (2011). Development of low cost household drinking water treatment system for the earthquake affected communities in northern pakistan. Desalination, 273(2-3), 316-320.

Möller, K., \& Burgschweiger, J. (2008). Wasserversorgungskonzept für Berlin und für das von den BWB versorgte Umland (Entwicklung bis 2040). Berlin, Germany: Report for BWB.

Murali, P., Ordóñez, F., \& Dessouky, M. M. (2012). Facility location under demand uncertainty: Response to a large-scale bio-terror attack. Socio-Economic Planning Sciences, 46(1), 78-87.

Murray, A. T. (2001). Strategic analysis of public transport coverage. Socio-Economic Planning Sciences, 35(3), 175-188.

Murray, A. T. (2013). Optimising the spatial location of urban fire stations. Fire Safety Journal, 62, 64-71.

Mwemezi, J. J., \& Huang, Y. (2011). Optimal facility location on spherical surfaces: Algorithm and application. New York Science Journal, 4(7), 21-28.

Nickel, S., Stein, O., \& Waldmann, K.-H. (2011). Operations research. Heidelberg: Springer.

Nolz, P. C., Doerner, K. F., \& Hartl, R. F. (2010). Water distribution in disaster relief. International Journal of Physical Distribution \& Logistics Management, 40(8/9), 693-708.

Peter-Varbanets, M., Zurbrügg, C., Swartz, C., \& Pronk, W. (2009). Decentralized systems for potable water and the potential of membrane technology. Water Research, 43(2), 245-265.

Privatinstitut für Transparenz im Gesundheitswesen GmbH. (2019). Betreutes Wohnen und Residenzen in Berlin. https://www.seniorenportal.de/betreutes-wohnen-in-berlin. Accessed 17 June 2020.

Redfern, R., Micham, J., Daniels, R., \& Childers, S. (2018). Something in the water: Hospital responds to water crisis. Disaster Medicine and Public Health Preparedness, 12(5), 666-668.

Riley, M. R., Gerba, C. P., \& Elimelech, M. (2011). Biological approaches for addressing the grand challenge of providing access to clean drinking water. Journal of Biological Engineering, 5(1), 2.

Rivera-Royero, D., Galindo, G., \& Yie-Pinedo, R. (2016). A dynamic model for disaster response considering prioritized demand points. Socio-Economic Planning Sciences, 55, 59-75.

Ruckart, P., Ettinger, A., Hanna-Attisha, M., Jones, N., Davis, S., \& Breysse, P. (2019). The flint water crisis: A coordinated public health emergency response and recovery initiative. Journal of Public Health Management and Practice, 25, 84-90.

Rundblad, G., Knapton, O., \& Hunter, P. R. (2010). Communication, perception and behaviour during a natural disaster involving a 'do not drink' and a subsequent 'boil water' notice: a postal questionnaire study. BMC Public Health, 10, 641.

Sanderson, D., Knox-Clarke, P., \& Campbell, L. (2012). Responding to urban disasters: Learning from previous relief and recovery operations. In $A L N A P$, November.

Shao, J., Wang, X., Liang, C., \& Holguín-Veras, J. (2020). Research progress on deprivation costs in humanitarian logistics. International Journal of Disaster Risk Reduction, 42, 10. https://doi.org/10.1016/j.ijdrr. 2019.101343.

Singh, L. K., Jha, M. K., \& Chowdary, V. M. (2018). Assessing the accuracy of gis-based multi-criteria decision analysis approaches for mapping groundwater potential. Ecological Indicators, 91, 24-37.

Sphere Project. (2018). The sphere handbook-humanitarian charter and minimum standards in humanitarian response. Geneva: Sphere Association.

Statistisches Bundesamt. (2019). Daten zur Energiepreisentwicklung - Lange Reihen von Januar 2005 bis August 2019. https://www.destatis.de/DE/Themen/Wirtschaft/Preise/Publikationen/Energiepreise/ energiepreisentwicklung-pdf-5619001.pdf;jsessionid=E9FD1C2DB6A0B38C62AD9A26DCDF4106. internet712?_blob=publicationFile. Accessed 17 June 2020. 
THW. (2012a). Trinkwasseraufbereitungsanlage THW. Bundesanstalt Technisches Hilfswerk (THW). https://www.thw.de/SharedDocs/Ausstattungen/DE/Geraete/trinkwasseraufbereitungsanlage.html? noMobile=1. Accessed 17 June 2020.

THW. (2012b). Verordnung über die Durchführung und Abrechnung von Hilfeleistungen des Technischen Hilfswerks. https://www.gesetze-im-internet.de/thw-abrv/THW-AbrV.pdf. Accessed 17 June 2020.

Toregas, C. (1970). A covering formulation for the location of public service facilities. Ithaca: Cornell University.

Träger, S. (2019). Micropur Forte MF 1T. https://www.krisenpakete.de/Micropur-Forte-MF-1T. Accessed 17 June 2020.

Tscheikner-Gratl, F., Egger, P., Rauch, W., \& Kleidorfer, M. (2017). Comparison of multi-criteria decision support methods for integrated rehabilitation prioritization. Water, 9(2), 68.

Umweltatlas Berlin. (2019a). Geoportal Berlin. https://fbinter.stadt-berlin.de/fb/index.jsp. Accessed 17 June 2020.

Umweltatlas Berlin. (2019b). Reale Nutzung 2015. https://fbinter.stadt-berlin.de/fb/index.jsp. Accessed 17 June 2020.

UNISDR. (2009). Terminology on disaster risk reduction. https://www.unisdr.org/files/7817_ UNISDRTerminologyEnglish.pdf. Accessed 17 June 2020.

Wannous, C., \& Velasquez, G. (2017). United Nations Office for Disaster Risk Reduction (UNISDR)UNISDR's Contribution to Science and Technology for Disaster Risk Reduction and the Role of the International Consortium on Landslides (ICL). In K. Sassa, M. Mikoš, \& Y. Yin (Eds.), Advancing culture of living with landslides (pp. 109-115). Cham: Springer International Publishing.

Wisetjindawat, W., Ito, H., Fujita, M., \& Eizo, H. (2014). Planning disaster relief operations. Procedia-Social and Behavioral Sciences, 125, 412-421.

Wu, J., Huang, C., Pang, M., Wang, Z., Yang, L., FitzGerald, G., et al. (2019). Planned sheltering as an adaptation strategy to climate change: Lessons learned from the severe flooding in anhui province of china in 2016. The Science of the Total Environment, 694, 133586.

Zimmermann, M., Felmeden, J., \& Michel, B. (2018). Integrated assessment of novel urban water infrastructures in frankfurt am main and hamburg, germany. Water, 10(2), 211.

Publisher's Note Springer Nature remains neutral with regard to jurisdictional claims in published maps and institutional affiliations. 